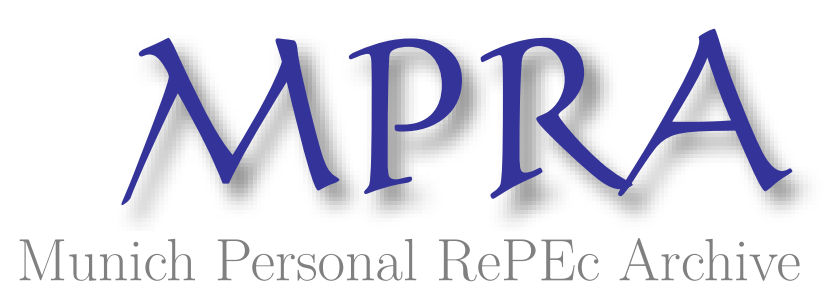

\title{
The making of heterodox microeconomics
}

Lee, Frederic

University of Missouri-Kansas City

12 May 2011

Online at https://mpra.ub.uni-muenchen.de/30907/

MPRA Paper No. 30907, posted 13 May 2011 21:58 UTC 
THE MAKING OF HETERODOX MICROECONOMICS

By

Dr. Frederic S. Lee

Microeconomic Theory: A Heterodox Approach

Chapter 1

May 12, 2011

Department of Economics

211 Haag Hall

University of Missouri-Kansas City

5100 Rockhill Road

Kansas City, Missouri 64110

U.S.A.

E-mail: leefs@umkc.edu 


\begin{abstract}
This paper constitutes the first chapter in my work-in-progress manuscript, Microeconomic Theory: A Heterodox Approach. Because many heterodox feel that the only micro theory is mainstream micro, the paper starts with a brief rejection of mainstream theory. It then proceeds to give an overview of heterodox economic theory. The third section defines heterodox microeconomic theory and relates it to heterodox value theory. Since heterodox economic theory and particularly microeconomic theory is not already formed, it has to be created. Thus the fourth section of the paper delineates the heterodox methodology of theory creation, which includes critical realism and the method of grounded theory, and discusses various methodological issues such as data, case studies, mathematics and modeling, and econometrics. The following section deals with the historical character of heterodox economic theories; and the paper ends with a discussion about the making of heterodox microeconomic theory that will take place in the subsequent chapters of the book.
\end{abstract}

Keywords: Heterodox, Microeconomics, Critical Realism, Grounded Theory

JEL Code: B5, B41, D0 


\section{THE MAKING OF HETERODOX MICROECONOMICS}

Economics as a discipline is a specialized, scientific, factual body of knowledge that endeavors to develop theoretical explanations of real economic activities that connect individuals with the goods and services needed to sustain their existence over time. The economic activities are not isolated or emenate from the efforts of an isolated individual, but rather are enmeshed with others to form a system of economic activities or the economy. Similarly, individuals are not isolated, but are enmeshed in various social relationships that cannot be stripped away. Together they imply that economic activities are an emergent system of social-economic activities that generate an array of goods and services needed to sustain the social individuals and their social relationships, and thus society as a whole. Consequently, economics is about developing theoretical explanations of the social provisioning process - that is economics is defined as the science of the social provisioning process. For any factual field of inquiry or scientific research field to exist, it must have a research community whose members exist in a society that at least tolerates if not supports their research activities. Moreover, its object of study must be real (as opposed to fictitious or non-existent) and relate to the problems and issues that are the focus of the research community. Finally, the methods used by the researchers to study the objects and address the problems and issues need to be grounded in the real world. Economics as a research field has a research community, albeit one divided between mainstream and heterodox economists, that are located within a society that supports it more (for mainstream economics) or less (for heterodox economics). The two sub-fields of economics, mainstream and heterodox economics, have some overlapping objects of study and problems and issues to address, but much less overlapping of methods used to study the objects and issues, which ultimately generate quite distinct theoretical and hence rival explanations of the social provisioning process. What makes mainstream and heterodox economics distinctly different is that the former, at 
a fundamental level, is not capable of developing coherent, theoretical explanations of the social provisioning process that are grounded in the real world. ${ }^{1}$

This claim merits further but brief discussion. First, the objects of study of mainstream economics, such as preferences-utility, marginal products, demand curves, rationality, relative scarcity, and homogeneous agents, are ill-defined, have no real world existence, and where relevant are non-quantifiable, non-measurable. ${ }^{2}$ Consequently, the issues and problems for which the objects are relevant, such as competitive markets, efficiency, and constrained optimality are either fictitious in that they are unrelated to the real world; or if the issues and problems are clearly located in the real world, such as prices or unemployment, the objects have no bearing on their existence. Secondly, the methods used by mainstream economists to develop theoretical explanations addressing the issues and problems, such as deductive methodology and ontological and methodological individualism, generally include fictitious objects and utilize concepts that have no grounding hence no meaning in the real world. Together, they clearly suggest that it is not possible for mainstream economists to conjure up any theoretical explanations relevant to the provisioning process that takes place in the real world. In addition, the mainstream theory of the provisioning process, which is as Hirshleifer argues (1985: 53) the core area of study of mainstream economics, is itself also quite problematical. The core propositions of the theory, such as scarcity, preferences and utility functions, technology and production functions, rationality, maximization/optimalization, market clearing, equilibrium, ontological and methodological individualism, heterogeneous agents, and positivist and deductivist methodology, have all been subject to intensive heterodox critiques; and in many cases there are multiple, overlapping heterodox critiques of core propositions. ${ }^{3}$ But even if the critiques are ignored, it is well-known that it is not possible to generate internally coherent explanations or stories or parables of market activity (such as the pervasive urban legend of the market as a self-adjusting 
mechanism) at either the micro or the macro level; and even if particular stories (represented in terms of models) of market activities are accepted, such as general equilibrium, game theory, or IS-LM, they have been shown, on their own terms, to be theoretically incoherent and empirically unsupported. The combination of critiques and incoherence means that none of the mainstream theoretical concepts or more generally its theoretical language and narrative story can be transferred to heterodox economics. [Rizvi 1994; Lawson, 1997a; Keen 2001; Lee and Keen 2004; Ackerman and Nadal 2004; White 2004; Petri 2004; Palacio-Vera 2005]

The above arguments suggest that mainstream theory lacks truth and value and contributes nothing (not even terms such as equilibrium, demand curve, or short period) to explaining the social provisioning process in a capitalist economy. Hence, it is not surprising that mainstream theory has become increasingly separated from its subject matter and progressively engaged in articulating properties of internally generated models. Nor is it surprising that its method of evaluating its fictional theories is to compare the projected fictional outcomes of a fictional model to actual data as if this had any meaning. Finally, it is not surprising that mainstream economists are increasingly defining economics as a particular method of inquiry without factual content. Given the fictitious nature of mainstream theory, it arguably represents bogus, false, or pseudo-knowledge because "it refers to non-existents or because it represents existents in an utterly false manner" (Bunge, 1983b, 195). Thus, mainstream theory is not a rival scientific theory to heterodox theory because it is not 'scientific', although it remains a non-scientific rival much like Creationism is non-scientific rival of the theory of evolution. ${ }^{4}$ The fact that it is considered part of the research field of economics indicates the extent to which economics is a highly contested discipline where non-scientific aims and attitudes still play a significant role. Therefore, economics is perhaps a protoscience or semiscience with heterodox economics representing pockets of an almost mature science. [Bunge, 1983b, 
1985, 1998; Mahner, 2007]

\section{HETERODOX ECONOMICS}

As stated above, economics is the science of the social provisioning process and that scientific endeavor is best carried out by heterodox economics. Heterodox economics refers to a specific group of theories aimed at explaining it, to economic policies recommendations predicated on the theories, and to a community of economists engaged in this theoretical and applied scientific activity. Heterodox economic theory specifically focuses on human agency in a cultural context and social processes in historical time affecting and directing resources and their usage, consumption patterns, production and reproduction, and the meaning (or ideology) of economic activities engaged in social provisioning utilizing empirically grounded concepts and an open system, grounded theory methodology. However, for the occurrence of such scientific activity, there must exists a research community of heterodox economists and its existence must be, to some degree, supported by society at large.

\section{Community of Heterodox Economists}

The scientific research community of heterodox economists is grounded in a social system of work that produces scientific or economic knowledge that contributes to the understanding of the economy and the social provisioning process. Moreover, this system of work is largely embedded in educational systems and their employment markets. So, although economic research and employment can be found in a variety of non-educational institutions, such as governments, private or public research institutes, trade unions, and advocacy organizations, the reproduction and expansion of the community is primarily tied to the academy. This means that the social system of work for heterodox economists is (as for mainstream economists) located in university economics departments. In particular, the department is the local employment market, establishes the career structure, is the 
organizational locale for teaching students and training future heterodox economists, and is the site for the production of heterodox scientific knowledge that must be publishable in referred journals, books, and other reputable outlets. ${ }^{5}$ In addition to university departments, there are other organizations that support and compliment the social system of work and support and promote the development of heterodox economic theory, including journals, book publishers, professional associations, and informal groups. Their importance is that they help sustain through their material property, financial support, and organizational activities, the various heterodox departments within the heterodox community. In turn, the departments, connected by various social networks, provide the positive critical rivalry necessary for intellectual creativity within the community.

The social network of heterodox economists consists of direct and indirect social relationships between heterodox economists. The relationships or social ties include correspondence; intellectual and social interactions at conferences, in seminars, or with students—such as teacherstudent relationship; and belonging to the same mailing lists, subscribing to and publishing in the same journals, attending the same conferences and seminars, and supporting a common course of action. Thus, a social network produces a connected and integrated body of specialized individuals who develop a common set of arguments, are concerned with a common set of questions and topics, and develop common standards for judging the arguments, answers, and discourse. In other words, the network acts as a chain of intellectual discourses where intellectual interaction through face-toface situations at seminars, in conferences, or over dinner brings together the intellectual community; focuses members' attention on and builds up vested interest in their own theoretical, historical, applied, and empirical topics and problems; and ties together written texts and lectures that are the long-term life of the community and gives its distinctiveness. The concatenated discourse that emerges from the face-to-face interaction keeps up the consciousness of the community's agenda and 
purpose by transcending all particular occasions of the interactions - that is, the discourse that emerges ensures that the community's purpose and agenda continue to be advocated independently of any individual member of the community or any specific face-to-face interaction. The discourse also has another impact in that it is the communicative process that creates thinkers within the community. [Lee 2009]

\section{Heterodox Economic Theory: Interpreting the Past for the Purposes of the Present with a View to Managing the Future ${ }^{6}$}

The intellectual and theoretical roots of heterodox economics are located in heterodox traditions of Post Keynesian-Sraffian, Marxist-radical, Institutional-evolutionary, social, feminist, and ecological economics, all of whom emphasize the social surplus, accumulation, justice, social relationships in terms of class, gender, and race, full employment, and economic and social reproduction. ${ }^{7}$ Hence, as a scientific research field, heterodox economics is concerned with explaining and proposing and advocating changes in the historical process of producing the social surplus that provides the flow of goods and services required by society to meet the reoccurring needs and promote the well-being of those who participate in its activities. That is, heterodox economics is a historical science of the social provisioning process, and this is the general research agenda of heterodox economists. Drawing from all heterodox approaches, its explanation involves both human agency embedded in a transmutable hence uncertain world with fallible knowledge and expectations and in a cultural context and social processes in historical time affecting resources, consumption patterns, production and reproduction, and the meaning (or ideology) of market, state, and non-market/state activities engaged in social provisioning. This implies that agency can only take place in an interdependent social context which emphasizes the social and deemphasizes the isolated nature ofindividual decision-making; and that the organization of social provisioning is determined 
outside of markets, although the provisioning process itself will, in part, take place through capitalist markets. Thus heterodox economic theory is a theoretical explanation of the historical process of social provisioning within the context of a capitalist economy; and hence it is also a historically contextual explanation. Therefore it is concerned with explaining those factors that are part of the process of social provisioning, including the structure and use of resources, the structure and change of social wants, structure of production and the reproduction of the business enterprise, family, state, and other relevant institutions and organizations, and distribution. In addition, heterodox economists extend their theory to examining issues associated with the process of social provisioning, such as racism, gender, and ideologies and myths.

Because heterodox economics involves issues of ethical values and social philosophy and the historical aspects of human existence, heterodox economists feel that it is also their duty to make heterodox economic policy recommendations to improve human dignity, that is, recommending ameliorative and/or radical social and economic policies to improve the social provisioning for all members of society and especially the disadvantage members. Moreover, they adopt the view that their economic policy recommendations must be based on an accurate historical and theoretical picture of how the economy actually works — a picture that includes class and hierarchical domination, inequalities, social-economic discontent, and conflict. The distinction between theory and policy is not the same as the positive-normative distinction found in mainstream economics. Heterodox theory is an explanation of how the social provisioning process actually operates, not how it is suppose to operate under 'ideal conditions'; while heterodox policy aims at altering the actual process to achieve a particular historically contingent outcome. Thus the ethos embedded in heterodox economic theory is that the social provisioning process is to be accurately explained so that it can be changed - an accurate explanation is not the same thing as a value neutral explanation, 
which implies that derivative economic policy is not value qua ethically neutral. [Polanyi 1968; Foster 1981; Gruchy 1987; Stevenson 1987; Dugger 1996; Bortis 1997; Hodgson 2001; Power 2004]

\section{Theoretical Core}

Since the economy is an emergent system with various sub-systems, the heterodox theory of the social provisioning process is also an emergent theoretical system with various theoretical subsystems. This implies that it cannot be divided into disjointed sub-systems of microeconomics and macroeconomics which in turn are based on quite different theoretical arguments. In particular, the core theoretical elements generate a three-component structure-organization-agency heterodox economic theory. ${ }^{8}$ The first component of the theory consists of the productive and monetary structures of the social provisioning process and together they form the structure of a real capitalist economy. The former represents production as a circular process in that the production of goods and services requires goods and services to be used as inputs. Hence, with regard to production, the overall economy (which includes both market and non-market production) is represented as an inputoutput table of resources, material goods, and services combined with different types of labor skills to produce an array of resources, goods, and services as outputs. Many of the outputs replace the resources, goods, and services used up in production and the rest constitute a surplus to be used for social provisioning, that is for consumption, private investment, government usage, and exports. The latter depicts the structural relationships between the wages of workers, profits of enterprises, and taxes of government and expenditures on consumption, investment, and government goods as well as non-market social provisioning activities which is facilitated by a flow of funds or state money accompanying the production and exchange of the goods and services. Together the two structures produce a monetary input-output structure of the economy as a whole where transactions in each market are a state-money transaction; where a change in price of a good or in the method by which a 
good is produced in any one market will have an indirect or direct impact on the entire economy; and where the amount of private investment, government expenditure on real goods and services, and the excess of exports over imports determines the amount of market and non-market economic activity, the level of market employment and non-market laboring activities, and consumer expenditures on market and non-market goods and services.

The second component of heterodox theory consists of three categories of economic organizations and institutions that are embedded in the monetary input-output structure of the economy. The first category is particular to a set of markets and products and consists of the business enterprise, private and public market organizations (such as cartels and government marketing boards) that regulate competition in resource, good, and service markets, and the organizations (such as trade unions) and institutions (such as minimum wage laws) that regulate the wages of workers. The second is spread across markets and products, or is not particular to any market or product and includes the state and various subsidiary organizations as well as particular financial organizations, that is, those organizations (such as Congress and the central bank) which make decisions about government expenditures and taxation, and determine the interest rate. Finally the third category consists of non-market organizations and institutions that promote social reproduction and include the household and state and private organizations (such as charities) that contribute to and support the household. The significance of organizations is that they are where agency qua the socialized individual, the third component of heterodox theory, is located. That is, agency, which consists of decisions made by individuals, concerning the social provisioning process and social well-being takes place through these organizations. And because the organizations are embedded in both instrumental and ceremonial institutions, such as gender, class, ethnicity, justice, marriage, ideology, and hierarchy as authority, agency acting through organizations affect both positively and negatively 
but never optimally the social provisioning process.

\section{HETERODOX MICROECONOMICS}

As argued above, the position adopted in this book is that heterodox economic theory is an emergent whole and the economy is conceived as a disaggregated interdependent system. ${ }^{9}$ Consequently, to theorize about the social provisioning process in terms of a disaggregated, interdependent economy, it is necessary to delineate and explain its constituent parts and their reproduction and recurrence, their integration qua interdependency by non-market and market arrangements and institutions, and how the system works as a whole, which implies examining how changes in one part of the economy produces changes in other parts as well as the economy as a whole. As a result heterodox microeconomics is concerned with delineating and explaining the constituent parts or sub-systems of the economy and their interdependencies, while heterodox macroeconomics is concerned with the economy as a whole and changes that occur as a result of changes in various parts of the economy. ${ }^{10}$

The sub-systems include the business enterprise and other private business organizations such as cartels, the household, and state-public organizations, while the interdependencies include technological-production relationships between enterprises, private investment-government expenditures and profit-employment, wages-capitalist income and workers-capitalist consumption patterns, state expenditures and taxes-financial assets. Heterodox microeconomic theory thus involves working with the sub-systems and interdependencies to develop analytical narratives, that is, theoretical explanations that contribute to understanding the social provisioning process. In principle, heterodox microeconomics consists of theories ranging from pricing, markets, and urban development to the household and the state. For this book, however, the scope will be limited to theorizing about the more traditional sub-systems and interdependencies. Because of the significance 
of the price mechanism to mainstream economics, one theoretical concern of the book is the business enterprise, markets, demand, and pricing. Also, since heterodox economists see private investment, consumption and government expenditures as the principle directors and drivers of economic activity, a second theoretical concern is business decision-making regarding investment and production, government expenditure decisions, the financing of investment, the profit mark up and the wage rate, and taxes. Finally, the third theoretical concern of the book is the delineation of a model of a going economy as a whole, which includes the productive and monetary structures of the social provisioning process, a price model, and an output-employment model. The integration of the theories of the business enterprise, markets, demand, investment, finance, and the state with a theoretical model of the going economy forms a nexus of theory that can be identified as heterodox microeconomics.

\section{Microeconomics and Heterodox Theory of Value}

Emerging from heterodox microeconomics contributions to the theoretical explanation of the social provisioning process are accounts about the origins of the social surplus (or the questions of the origins of profits, wages, and rents) and access to the provisioning process (or the question of producing and distributing the surplus). Through dealing with these issues, the theoretical narrative of the provisioning process is transformed it into a theory of value. That is, a theory of value is a narrative which is linked to a quantitative analysis (usually a model or a concatenated set of models) that succinctly explains why and how the particular goods and services that constitute the social provisioning process get produced and the households, business enterprises, and the state get access to them. Consequently, the particulars of the explanation include the origins of the income variables (wage rates and profit mark ups) that give access to the surplus and hence to the provisioning process; the determination of prices and their role in affecting economic activity; the determination 
of the social surplus, total social product, and employment; the 'real costs' of producing the social surplus; the distribution of the consumption goods between and within the three social classes; and the distribution of fixed investment goods and state financial assets among business enterprises (Dobb 1945: 1-33). The explanation also includes an examination of the state as the political unit in which the provisioning process is located and its role in affecting and directing economic activity.

The narrative of heterodox value theory is quite explicit as it is brief. It starts (and also ends) with the observation that the material basis of the social provisioning process is determined by the ruling class - the capitalist class and the political elite of the dependent capitalist state - for society as a whole. This is possible since the composition and amount of the total social surplus is determined by the ruling class, they have the dominant influence qua control over the economy and society; and since the capitalist class via the business enterprise administratively set going enterprise prices, profit mark ups, and wages while the state sets wages, employs people, and makes government and interest payments, the ruling class determines through non-market decisions both the general access and the differential access to social provisioning. Expanding upon the narrative, the ruling class determines the surplus goods and services they want and hire the surplus labor to produce them; and the production of surplus goods and services for workers are an unintended byproduct. That is to say, the production decisions are controlled by the ruling class. This means that the capitalists' decision to produce consumption goods and services for workers governs the workers' access to the social provisioning process by simultaneously creating the wage rate as an income category. In a similar manner, the capitalists and state decisions to produce fixed investment and consumption goods and services for the capitalists and for the state governs the capitalists' and the state's access to the social provisioning process by simultaneously creating the profit mark up and state money as a income categories. In short, because the capitalist class and the state determine the 
production of the surplus and with it wage rates, profit mark ups, and state money, they govern the real direction of the capitalist economy, control the volume of and access to the social provisioning process (while the price system plays a secondary role of governing the access of particular capitalists and workers to social provisioning and ensuring the reproduction of the business enterprise), and maintain the capitalist (dominate)-worker (subordinate) social relationships necessary for capitalism to exist. What this clearly implies is that the creation and distribution of the surplus is effectuated through the social relationships that sustain the ruling class, while the trappings of market forces are a veil that obscures them; or more strongly put: it is social relationships couple with social agency that are the primary movers of economic activity and the provisioning process while the role of markets and the price system play both a secondary role and an obscuring role. Heterodox microeconomics pierces this veil and reveals what is hidden and obscured.

\section{METHODOLOGY OF HETERODOX ECONOMICS}

Heterodox economic theory is not a pre-existing doctrine to be applied to an invariant economic reality — it just does not exist ahistorically ready for application. There are, of course, many theoretical arguments that have been advanced which appear to contribute to its construction but there is no reason why they should command blind acceptance and, in any case, they fall short of making a comprehensive theory. Consequently, new factual theories are needed to fill the gaps. In either case, there needs to be a basis for accepting the theories as reasonable scientific theoretical contributions to explaining the social provisioning process. This suggests that the delineation of heterodox microeconomic theory takes the form of theory creation. Scientific theory creation requires a methodology for the task and the methodology is the method of grounded theory, and its philosophical foundation of realism, critical realism, and epistemological relativism.

\section{Philosophical Foundation}


Being both participants in and observers of the social and economic activity around them, heterodox economists approach their study of economics with a common sense understanding of the world. By common sense, it is meant a complex set of beliefs and propositions (many of which are historically grounded) about fundamental features of the world that individuals assume in whatever they do in ordinary life. Thus, they take particular features, characteristics, institutions, and human actors of economic activity as real, obvious, and practical initial starting points for further research. To be real, obvious, and practical means that various features, institutions, and actors exist, are ingrained everyday properties of the world of economic activity, and are encountered when observing or participating in ongoing economic activity. In particular, heterodox economists can, as observers, see them in action in the economy; or they can directly experience them as participants in economic activity. By being a participant-observer, they are able to be close to the real, concrete form of the economy. Consequently their common sense beliefs and propositions provide the background against which they carry out their research. Hence, this common sense understanding of economic activity informs the methods which heterodox economists actually use to examine economic activity, particularly with regard to the way it is explained. [Coates 1996; Maki 1989, 1996, 1998a, 1998b; Dow 1990a, 2001]

Heterodox economists characterize their common sense propositions by stating that the real (actual) economy is a non-ergodic, independent system with human agency and economic-socialpolitical structures and institutions embedded in an historical process located in historical time. Other propositions accepted and articulated which support and clarify the above include: the actual economy and the society in which it is embedded is real and exists independently of the heterodox economist; the economy is transmutable, hence its future is uncertain and unknowable; ends are not entirely knowable nor independent of the means to achieve them; economic change comes about 
through human action interacting with social, political, and economic structures and institutions; human action is derived in part from ethical, cultural, political, and ideological beliefs so that economic outcomes are also ethical and political outcomes as well; and a capitalist society is a class society and the economy is permeated with hierarchical power derived in part from it. The final common sense proposition is that the study of particular economic activity cannot be done independently of the whole economy or from the social system in which it is embedded. Mutually shared among heterodox economists, these common sense propositions provide the basis for its ontological realism foundation. [Wilber and Harrison 1978; Gruchy 1987; Lawson 1994, 1999a; Arestis 1996; Davidson 1996; Dow 1999, 2001; Downward 1999; Rotheim 1999]

From the common sense propositions, heterodox economists conclude that the economy works in terms of causal-historical processes. Moreover, because they accept the ontological constraint implicit in this, a specific form of realism, critical realism, is the ontological basis of heterodox economics. Not only do they posit that economic phenomenon are real, heterodox economists also argue that their explanations or factual theories refer to real things, represent real entities, are judged good or bad, true or false by virtue of the way the economy works, and are causal explanations. ${ }^{11}$ As a causal explanation, theory provides an account of the process as a sequence of economic events and depicts the causes that propel one event to another in a sequence. In addition, while accepting at the minimum a correspondence theory of truth with regard to evaluating theories, they also accept epistemological relativism, which is that knowledge of economic events is historically contingent, and integrate the two. Finally, to ensure that their factual theories are causal explanations of real things, heterodox economists adopt the methodological guideline of the method of grounded theory. [Maki 1989, 1992a, 1996, 1998a, 1998b, 2001; Ellis 1985] 
Critical Realism

Critical realism starts with an account of what the economic world must be like before it is investigated by economists and for economic analysis to be possible. Thus its fundamental claim is that the economic world is causally structured which means, as will be subsequently argued, that economic theories are historical and narratively structured. Critical realism begins with four propositions, the first being that the economic world consists not only of events and our experiences, but also of underlying structures and causal mechanisms that are in principle observable and knowable. Second, it is argued that economic events, structures and causal mechanisms exist independently of their identification. Third is the argument that all economic events are produced by an underlying set of causal mechanisms and structures. Finally, as an a posteriori observation, it is commonly noted that the social world is open in that economic events are typically produced as a result of interactions of numerous, often counteracting structures and contingently related causal mechanisms. Consequently, there is a three-tier view of economic reality. The first two tiers are the empirical events of experience and impression and the actual events underlying them. Understanding the former depends on the explanations of the actual events and that is derived from causal mechanism(s) and economic structures, which constitute the third tier of economic reality. The causal mechanisms and structures together are the ontological core of heterodox economics in that when they are identified and understood, the empirical and actual events are jointly understood. Moreover, because causal historical processes are knowable and observable, so are the causal mechanisms and structures. Thus for the heterodox economist, identifying structures and causal mechanisms and describing their way of influencing or acting on specific events in the open economic world is their scientific undertaking; putting critical realism into practice thereby making the unknown knowable and the unseen observable although it will not be perfect. ${ }^{12}$ 
A causal mechanism in the context of heterodox economics is irreducible, has a relatively constant internal organization whose components are intentionally not mechanistically related, is real, observable, and underlies, hence governs or produces actual events, and acts transfactually (that is acts and has effects even when it does not generate discernable actual events). ${ }^{13}$ Being irreducible means that the form and organization cannot be disaggregated into its constituent components and still function as a causal mechanism. In this sense, a causal mechanism is an emergent entity in that its properties and powers cannot be completely traced to its individual components. To have a constant form and organization means that the mechanism can be empirically identified by stable patterns of behavior and organizational format and hence empirically observed and delineated. Furthermore, the ability to act means that the mechanism has the power to generate qualitative and/or quantitative outcomes; and the triggering of the mechanism comes from agency, human intentionality. Thus economic actors have independent power to initiated actions, therefore setting in motion causal mechanisms which generate outcomes that underlie hence govern actual economic events. Because the causal mechanism utilizes the same processes when producing results, the same results are repeatedly produced; and conversely, a causal mechanism does not produce accidental, random, transitory results. ${ }^{14}$ So to say that a causal mechanism acts transfactually producing the same results is also to say that its form and internal organization are constant thereby making it a relatively enduring entity. Hence, if the same causal mechanism operates in different situations, it will produce the same, or transfactual, results each time it is in operation; but the empirical and actual events need not be regular or repeatable, as other contingently related causal mechanisms may be affecting them. However, in an open system, a causal mechanism only has the tendency to produce regular, repeatable qualitative or quantitative actual economic events denoted as demiregularities. 
Structure is different from causal mechanism in that it does not include human agency, hence it can only help shape or govern the actual event. Otherwise it is similar to a causal mechanism in that it is real, observable, relatively enduring in form and organization, irreducible, and governs transfactually. The structures of an economy have two additional properties: (1) being sustained, reproduced, and slowly transformed by economic and social events that are caused by human action through their causal mechanisms; and (2) their form and organization have a historical character. Moreover, all economic structures are social structures in that they represent and delineate recurrent and pattern interactions between economic agents or between economic agents and technology and resources. Economic structures include economic and social norms, practices and conventions, social networks such as associational networks or interlocking directorates, technological networks such as the production and cost structures of a business enterprise or the input-output structure of an economy, and economic, political, and social institutions such as markets or the legal system. As distinct entities, neither causal mechanisms nor structures can separately cause and govern actual economic events. Rather they must work jointly where the structures provide the medium or the conditions through which causal mechanisms via human agency act. So, as long as they remain enduring, there will be a tendency for regular and repeatable actual economic events to occur. In fact, in a transmutable world where the future is not completely knowable, agency is only possible if causal mechanisms and structures are relatively enduring so that the agents can connect their acts to outcomes; for if agents could not see themselves producing transfactual results, they would not act. ${ }^{15}$ [Maki 1989, 1998b; Lovering 1990; Kanth 1992; Sayer 1992; Lloyd 1993; Lawson 1994, 1997a, 1997b, 1998a, 1998b, 1998c; Ingham 1996; Lawson, Peacock, and Pratten 1996; Wellman and Berkowitz 1997; Fleetwood 2001a, 2001b; Hodgson 1998, 2000; Joseph 1998; Dow 1999; Downward 1999; Rotheim 1999] 


\section{Epistemological Relativism}

Epistemological relativism is the view that knowledge of economic events is historically contingent. That is, because the social and economic activities of interest to heterodox economists change over time, knowledge and understanding of them is historically contingent; hence there are no eternal 'truths' and knowledge is always in the process of being created, even for past events. Consequently, what is known about actual economic events of the past need not be knowledge about current or future economic events. As a result, heterodox economists are continually engaged in creating new knowledge, new explanations to take the place of those that cease to refer to real things, represent real entities, and explain actual economic events. Thus explanations or theories are historically conditioned hence historically contingent, which implies that, for heterodox economists, there are no ahistorical economic laws or regularities. Moreover, it is not possible to make ahistorical, general statements with absolute certainty beyond the historical data and context in which the statements are embedded. Another implication is that theories must be, in some sense, grounded in historical data in order to tell historical stories explaining historical economic events. A third implication is that the difference between good and not-so-good, between true and simply plain wrong theories is how well their explanations correspond if not 'embody' to the historically contingent economic events being explained. Finally, epistemological relativism implies that the continual creation of knowledge is a social act carried out by informed actors, that is by heterodox economists, in a socially, historically contingent context. [Sayer 1992; Lawson 1997a; Pratt 1995; Yeung 1997]

\section{Method of Grounded Theory}

To develop a factual theory that analytically explains causally related, historically contingent economic events, the critical realist heterodox economist needs to identify and delineate the 
structures, causal mechanisms, and causal processes producing them. The methodological guideline for creating causally factual explanatory theories that is also consistent with realism, critical realism, and epistemological relativism is the method of grounded theory. ${ }^{16}$ The method of grounded theory can be described as a guideline qua process by which researchers, or more specifically economists, create their theory 'directly' developed from data (which are not the same as the 'objective facts' of the empirist); and in which data collection, theoretical analysis, and theory building proceed simultaneously--see Figure 1.1. ${ }^{17}$ The use of the method begins with the economist's becoming familiar with, but not dogmatically committed to, the relevant theoretical, empirical, and historical literature that might assist them in approaching, understanding, and evaluating the data relevant to their research interest. Then, one engages in 'field work' by collecting comparable data from economic events from which a number of specific categories or analytical qua theoretical concepts and their associated properties are isolated and the relationships between them identified. With the theoretical concepts and relationships empirically grounded in detail and hence empirically justified, the economist then develops a theory in the form of a complex analytical explanation based on the data's core concepts. The essential property of the theory is that it explains why and how the sequence of economic events represented in the data took place. Hence, the economist does not attempt to construct a simplified or realistically deformed empirically grounded theory by ignoring or rejecting particular data. Rather, the economist endeavors to capture the complexity of the data by establishing many different secondary concepts and relationships and weaving them together with the core concepts into structures and causal mechanisms. This ensures that the resulting theory is conceptually dense as well as having causal explanatory power. The process of selecting the central theoretical concepts and developing the theory brings to light secondary concepts and relationships that also need further empirical grounding, as well as suggesting purely analytical concepts and 
relationships which need empirical grounding if they are to be integrated into the theory. After the theory is developed, the economist will evaluate it by seeing how it explains actual economic events.

Figure 1.1

Schema of the Grounded Theory Method

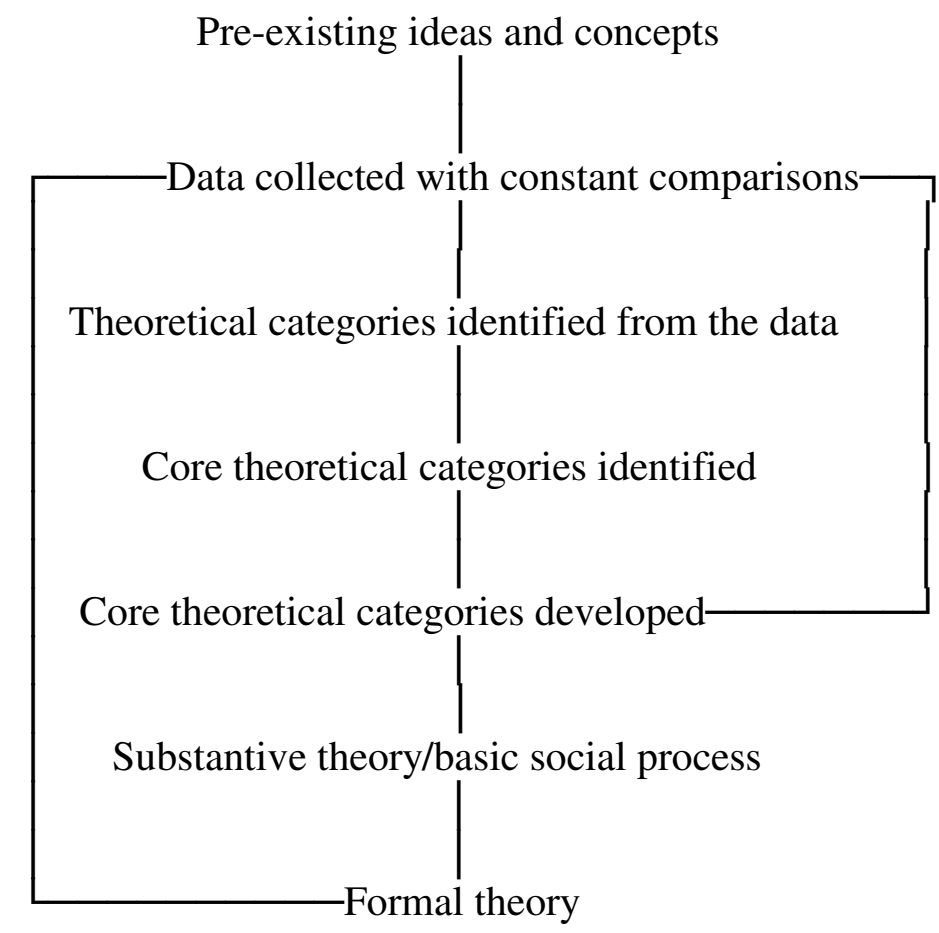

Let us now consider aspects of the grounded theory method in more detail. First, the collection of data is a complex task that involves collecting the data themselves, that is counting up pieces of data, as well as constantly comparing, analyzing, and interpreting the data collected while simultaneously organizing them into generalized categories qua theoretical concepts. The theoretical categories that emerge come from the data themselves, not after they are all collected, but in the process of collecting them. ${ }^{18}$ Consequently each category is tied to or empirically grounded in its data; and since the data is real, observable, measurable, so is the theoretical category. ${ }^{19}$ Moreover, since the data lies in time and history, each theoretical category is anchored in a particular historical 
setting. In short, a grounded theory category is theoretical and actual, grounded in real time, and historically specific.

The purpose of constant comparison of the data is to see whether they support and continue to support emerging categories. ${ }^{20}$ Thus, each theoretical category that becomes established will have been repeatedly present in very many comparable pieces of data derived from multi-sources. ${ }^{21}$ In this way individual pieces of data that would not be significant on their own obtain a collective, emergent significance. The categories that emerge are of two types: one that is derived directly from the data and the other that is formulated by the economist. The former tends to denote data self-description and actual processes and behavior while the latter tend to denote explanations. ${ }^{22}$ In addition, each category will have properties also derived from data in the same manner, that is, by using constant comparisons. The more properties a category has, the denser and hence the more realistic it is. A grounded theory category does not ignore the complexity of reality; rather it embraces it.

In the process of collecting data, the economist may feel that what is being collected is not revealing additional properties of a specific kind that they believe, owing to their familiarity with the relevant theoretical, empirical, and historical literature, might exist. As a result, the economist will engage in theoretical sampling. This involves sampling or collecting data that are expected to increase the density of a specific category by producing more properties, as well as increasing the number of pieces of data supporting each of the properties, hence making it more definitive and analytically useful. $^{23}$ Theoretical sampling and collection of data for a single category, as well as for a range of categories, continues until theoretical saturation is reached, that is when no new data regarding a category and the relationships between the categories continue to emerge. ${ }^{24}$ The significance of this empirical grounding process is that the theoretical categories cannot be unrealistic hence false since they are derived from the data. If the data collection and theoretical sampling is 
incomplete then the categories will not be adequately dense, as relevant properties will be missing; thus such categories will be incompletely realistic. On the other hand, if future data emerges which the empirical grounding process shows do not fall into a previously existing category, then that category is not relevant, but it is not empirically false.

Once the real, observable theoretical categories are delineated and grounded, the economist, perceiving a pattern of relationships among them, will put critical realism into practice by classifying some directly as economic structures and others as components of economic structures. Continuing the practice, other categories that centered on human motivation and action and a set of outcomes will be woven together into a causal mechanism. The resulting structures and causal mechanisms will be real, observable as opposed to unreal, metaphoric, and hidden. That is, to observe a structure or causal mechanism is to observe the working together of its observed concrete components, including the human actions involved, much as a family is observed through the interaction of its members. Hence structures and causal mechanisms are real, observable precisely because their categories are real and observable.

Given the research interest, the economist will select from the causal mechanisms identified, one as the central causal mechanism around which the structures and secondary causal mechanisms with their outcomes are arranged. Criteria for selecting the central causal mechanism from among a number of possible causal mechanisms include the following: that it appears frequently in the data as a cause of the outcomes, that it has clear implications for a more general theory, and that it allows for complexity. Thus the causal mechanism is central to the narrative to be analytically developed in conjunction with the economic structures and secondary causal mechanisms. More specifically, the narrative is not a description of present or a recounting of past unique and/or demi-regular economic events, although both techniques of presenting empirical and actual economic events are included in 
the narrative. Rather, it is a complex analytical explanation of those described or recounted events. Even when the basic narrative is decided upon, its development will involve further theoretical sampling and collecting of data as new properties for the existing structures and causal mechanisms emerge. Consequently, the narrative evolves into an economic theory while at the same time becoming increasingly denser (in terms of properties and empirical grounding) as well as increasingly complex.

The complexity arises because of the variations in the categories and in the properties of the categories that make up the theory. The grounded economic theory that eventually emerges is a complex analytical explanation or interpretation of the actual economic events represented in the data. Thus the theory is not a generalization from the data, but of the data; that is, a grounded theory does not go beyond the data on which it is based--it does not claim universality or the status of an empirical-theoretical law. ${ }^{25}$ In addition, since the theory is a clear theoretical account of empirical and actual events that occur in historical time, the three-tier view of economic reality collapses into a single integrated tier for the heterodox economist. With the grounded theory in hand, the heterodox economist can directly "see" the causal mechanisms and structures and "hear" the economic actors determining the empirical and actual events - the mysterious, randomness, and unintelligibility is replaced by clear explanation. Moreover, being a weave of a central causal mechanism, secondary causal mechanisms, and economic structures designed to explain actual economic events in historical time, the theory also consists of descriptively realistic (as opposed to stylized or fictionalized) descriptions of economic events and accurate narratives of sequences of economic events. As a result, the grounded economic theory is an emergent entity, a concatenated theory that cannot be disassembled into separate parts. Hence the question of logical coherence of a deductivist kind cannot be applied to a grounded theory; instead the coherence of the theory is judged on how well its 
explanation corresponds to the actual historically contingent economic events. ${ }^{26}$

Economic theory centered on a single central causal mechanism is classified as a substantive economic theory since it is an explanation of a single basic economic process that occurs widely in the economy. From a number of substantive theories, a formal economic theory can be developed into a general or holistic theory where the relationship or pattern among the substantive theories is its analytical explanation. ${ }^{27}$ As in the process of grounding the substantive economic theory, the formal theory also has to be grounded. In particular, the relationships between the substantive theories that constitutes the formal theory need to be grounded in data assisted and directed by theoretical sampling. Consequently, the formal economic theory is grounded, historically contingent, and its analytical explanations are not empirical extrapolations. As the economic world is not static, a formal theory is never complete, but undergoes continual modification with ever newer data relating to newly emerging patterns or configurations of economic reality.

There are two aspects of the grounded theory method that need further delineation. The first deals with the role of pre-existing ideas, concepts, and categories, that is, the issue that all observations, data and descriptions are theory laden. To use the method fruitfully, the heterodox economist must become familiar with the contemporary theoretical and non-theoretical literature, the controversies between economists, and the relevant literature from the history of economic thought. ${ }^{28}$ In particular, they need to make a detailed and critical investigation of the pre-existing heterodox ideas and concepts to see which lend themselves to empirical grounding. The economist also needs to be familiar with some of the empirical literature as well as with the relevant literature from economic history. By acquiring a critical awareness of the pre-existing economic theories and empirical findings, the economist acquires a theoretical sensitivity regarding the data and theoretical concepts they will be examining, comparing, and empirically grounding. As a result, the economist 
will have the ability to recognize what might be important in the data and to give it meaning as well as recognizing when the data do not support a pre-existing theoretical concept or category, requires a large or small transformation of the pre-existing concept or category, or 'produce' a new category. Thus, the grounded theory method not only recognizes that observations, data, and descriptions are theory laden, it reinforces the latter by demanding that all economists enter into theory creation as theoretically knowledgeable and aware individuals, as well as with the conviction that the creation of a new substantive economic theory will most likely require them to set aside forever some of that acquired knowledge. ${ }^{29}$ By acknowledging the issue of theory-laden observations while at the same time demanding that the economist be skeptical of all pre-existing theory, the grounded theory method is a highly self-conscious, engaging and open-minded approach to economic research, data creation-collection, and theory building.

The second aspect deals with evaluating a grounded theory. It is noted above that, since the categories that constitute the theory are intimately linked with the data, the grounded theory itself can not be falsified. More specifically, because a grounded theory is developed with the empirical data rather than prior to it, it does not stand independently of the data. Thus, it is not possible to test for the truth or falsity of a grounded theory by checking it against the independently given empirical evidence. But a grounded theory can be evaluated by how well it explains actual economic events, that is how well it identifies empirically and weaves together the causal mechanisms, structures, and descriptions into a narrative of the economic events being explained. In short, a grounded theory refers to real things, represents real entities, and is evaluated on how well it corresponds to the causal way the economy actually is. ${ }^{30}$ The evaluation process takes place within a community of scholars, in that papers delineating tentative drafts of the theory are presented to colleagues at conferences and seminars for critical comments; and more refined presentations of the theory are published where 
colleagues have the opportunity to point out inadequacies. Through this cooperative process of economic-writing, economic-reading, and critical commentary, the community of heterodox economists arrives at adequate theories, which clearly illustrates the social nature of knowledge construction. ${ }^{31}$ Consequently, a grounded theory is, in the first instance, only as good as its theoretical categories. If the data selected do not cover all aspects of the economic event(s) under investigation; if the economist compiles categories and properties from only part of the data collected or forces data into pre-determined categories; if the density of the categories is small or the relationships between categories under-grounded due to incomplete data collected; if the economist choose the 'wrong' central causal mechanism; and/or if the narrative is static, terse, unable to fully integrate structures and central and secondary causal mechanisms, and relatively uncomplex, then the commentary of critics will make it clear that the economic theory is poor, ill-developed hence to a greater or lesser extent unrealistic, and unable to provide a comprehensive and convincing explanation of actual economic events. ${ }^{32}$ As a result, the economist will have to begin the theory creation process anew.

A second way to evaluate a grounded economic theory is to see how well it deals with new data. That is, the relatively enduring structures, causal mechanisms and their outcomes of a grounded theory are based on data collected in a specific time period. Thus, it is possible to evaluate whether they have remain enduring outside the time period by confronting them with 'new' data derived from replicating studies, especially data from actual events that at first glance appears to fall outside existing categories and not to support expected transfactual results. If the new data falls within the existing categories and conforms to the transfactual results, then the structures and causal mechanisms have been relatively enduring. ${ }^{33}$ On the other hand, if the new data falls outside the existing categories and not supporting the transfactual results, then at least some of the structures and 
causal mechanisms have changed. Consequently, the existing grounded economic theory needs to be modified or replaced by a completely new one. Therefore, theory evaluation in the grounded theory method based on the introduction of new data is designed to check the continual correspondence of the theory with the real causes of ongoing unique and demi-regular economic events. Hence, it is essentially a positive way of promoting theory development and reconstruction as well as new theory creation when the correspondence between theory and events breaks down.

The fact that good or poor research practices lead to better or worse grounded economic theories indicates that choices made by economists do affect the final outcome. Therefore, within the grounded theory method it is possible, although not likely, to have good but different substantive and formal economic theories for the same economic events. Given the same theoretical categories, a different choice of a central causal mechanism will produce a different theory; or if the same central causal mechanism is used but integrated with different structures and secondary causal mechanisms a different theory will also be produced. ${ }^{34}$ However, since heterodox economists are realists and critical realists, and their theories concern causal historical events, they do not accept the possibility that there is no empirical data that could distinguish between two incompatible theories. Thus, following the same procedures as above, the way forward for the grounded theorist would be to collect new data to see which of the two theories they support supplemented by critical commentary from colleagues. Hence, although the procedures used are the same and the data collected are, in principle, the same, checking the continual explanatory adequacy of a grounded theory is a different activity from choosing between two different theories, for the former produces a historically linked sequence of grounded theories, while the latter concludes that one of the two theories is not an explanation after all. [Annells 1996; Glaser and Strauss 1967; Conrad 1978; Turner 1981, 1983; Charmaz 1983; Strauss 1987; Konecki 1989; Strauss and Corbin 1990, 1994; Corbin and Strauss 
1990; Glaser 1992, 2007; Dey 1999, 2007; Finch 1999, 2002; Tsang and Kwan 1999; Bigus, Hadden, and Glasner 1994; Tosh 1991; Diesing 1971; Wilber and Harrison 1978; Fusfeld 1980; Gruchy 1987; Wisman and Rozansky 1991; Boylan and O'Gorman 1995; Atkinson and Oleson 1996; Runde 1998; Sayer 1992; Megill 1989; Emigh 1997; Maki 1990, 2001; McCullagh 2000; Hunt 1994; Pentland 1999; Ellis 1985; Lewis and Grimes 1999]

\section{Methodological Issues}

The grounded theory method of theory creation effectively dismisses not only the traditional issue of the realisticness of assumptions but also the role of assumptions in theory creation and development. That is, since assumptions as a basis for theory creation are not part of the grounded theory method and hence not grounded in the real world, the degree of their realisticness or their adequacy as a logical axiomatic foundation for theory is not a concern. As noted above, this implies that logical coherence is irrelevant for evaluating grounded theories. Moreover, because the role of theoretical isolation in traditional theory building and theorizing is dependent on assumptions, their absence in the grounded theory method means that grounded theories are not isolated theories that exclude possible influencing factors. The combination of critical realism, with its structures, causal mechanisms, and epistemological relativism, and the grounded theory method produces theories that include all the relevant factors and influences, are historically contingent, and exist in 'real' space and time. To deliberately exclude some factors would leave the mechanisms, structures, and theories insufficiently empirically grounded; and to claim to establish laws and certain (timeless) knowledge would remove the mechanisms, structures, and theories from the real world economic events they are to explain. Thus, the integration of critical realism and grounded theory results in theories and theorizing fundamentally different from the traditional mode. ${ }^{35}$ In particular, it means that heterodox economic theory is not an axiomatic-based approach to theory creation, does not use deductivist 
methods to create theory, and rejects every method of theory creation that is not empirically grounded. On the other hand, their integration produces their own set of methodological issues, centering on the nature of data, the case study method, mathematics and economic models, and econometrics. [Spiethoff 1953; Maki 1989, 1992a, 1992b, 1998b]

\section{Data}

Originally, the grounded theory method was developed as a way to utilize qualitative data to build a theory; however, the use of quantitative data was not excluded. As economists are interested in developing historically grounded explanations of past and present economic events, their possible sources of data include all existing written, recorded, physical, and quantitative records. Since existing data sources might provide an incomplete record of economic events, the economist must also utilize different research strategies--such as surveys, interviews and oral statements, ethnographic and industrial archaeology studies, questionnaires, mapping, direct observation, participation in activities, fieldwork, and statistical analysis--to create new qualitative and quantitative data. ${ }^{36}$ In this context, subjective evaluations and interpretations of future possibilities constitute a particular kind of qualitative data that require particular research strategies to observe and record. ${ }^{37}$ For example, when it is important to explain how and why particular business decisions are made and who made them, the economist will need to create narrative accounts of relevant lived-historical experiences embedded within the cultural milieu of particular business enterprises. Thus they will need to examine letters and other written documents, undertake interviews and other oral documentation, and possibly engage in participant observation in which the economist may directly engage with, for example, the enterprise in the process of collecting data. What constitutes appropriate data depends on the object of inquiry; but it is important that much of the data deals with process, intentionality and their outcomes. Consequently, real, observable, and 
measurable theoretical categories, hence real, observable, and measurable economic structures and causal mechanisms, are empirically grounded in both qualitative and quantitative data obtained from various sources. Thus, the analytical narrative or theory is grounded in many different types of data. ${ }^{38}$ [Goulding 2002]

\section{Case Study}

The theoretical categories that make up grounded theories are based on an array of comparable data generated by case studies. A case study is defined as an in-depth, multifaceted investigation of a particular object or theme where the object or theme gives it its unity. The object or theme can be historical or a current real-life event and the study will use several kinds of qualitative and quantitative data sources. For example, the theme of a case study can be the pricing procedures used by business enterprises; consequently the case study will be the collection, comparison, categorization, and tabulation of pricing procedures obtained from various empirical pricing studies along with a critical narrative that examines and integrates the data. Thus, the case study approach is the principle method of qualitative and quantitative data collection and comparison used to develop categories, structures, and causal mechanisms. Moreover, by providing information from a number of different data sources over a period of time, it permits a more holistic study of structures and causal mechanisms.

A case study does not stand-alone and cannot be considered alone; it must always be considered within a family of comparable case studies. If the economist is faced with a shortage of case studies, the response is not to generalize from them but to undertake more case studies. Moreover, theoretical sampling is specifically carried out through case studies in that the economist makes a conscious decision to undertake a particular case study in order to increase the empirical grounding of particular theoretical categories. ${ }^{39}$ Thus a case study can be of an individual business 
enterprise and the theme of the study can be to delineate the complex sets of decisions regarding pricing, production, and investment and to recount their effects over time. On the other hand, it can be concerned with a particular theoretical point, such as pricing, examined across many different case studies of different enterprises. The different cases not only provide comparable data for comparisons but also descriptions of structures and causal mechanisms and a narrative of the causal mechanism in action over time. A third type of case study is a narrative that explains an historical or current event. The narrative includes structures and causal mechanisms which, when combined with the history or facts of the event, explains how and why it took place. Hence, this type of case study is both a historical and theoretical narrative, an integration of theory with the event. Consequently, it provides a way to check how good the theory is and, at the same time, contributes to its grounding and extension. A robust substantive theory is one that can be utilized in an array of case studies of historical and current events. ${ }^{40}$ [Smith 1998; Stake 1998; Eisenhardt 1989; Orum, Feagin, and Sjoberg 1991; Wieviorka 1992; Vaughan 1992; Finch 1999, 2002; Scheibl and Wood 2005; Yin 1981a, 1981b, 1994; George 1979; Sayer 1992]

\section{Mathematics and Economic Models}

Mathematics and economic models are useful as tools and instruments that can contribute to the development and evaluation of causal mechanisms and grounded theory. Their uses are, however, restricted since the tenets of realism, critical realism, and the method of grounded theory prescribe that the type of mathematics used and factual economic models constructed are derived from (as opposed to being imposed upon via analogy or metaphor) the empirically grounded theories being developed. Consequently, the economic model reflects the narrative of the theory from which

it is derived. ${ }^{41}$ Model building involves translating a grounded theory into a factual economic model, which means its structures and causal mechanisms (which embody accurate measurements and 
observations) have to be converted, as far as possible, into mathematical language where each mathematical entity and concept is in principle unambiguously empirically grounded, meaning in part they also have to be measurable and observable. As a result, the mathematical form of the model is determined and constrained by the empirically grounded structures (such as the input structures of a input-output model) and causal mechanisms (such as investment decisions by business enterprises), and hence is isomorphic with the theory and its empirical data. ${ }^{42}$ In this manner, mathematical model-based analysis is derived from and remains subjugated to the study of agency-structure determined economic activity. If an economic model has only empirically grounded structures and no agency, then it is not well-grounded and nor are its solutions; and if the model's structures and agency are not empirically grounded, then its outcomes have no meaning. Thus, while mathematics helps illuminate aspects of the grounded theory and making clear what might be obscure, it does not add anything new to the theory. That is, it does not by itself produce new scientific knowledge; or more strongly, it is not possible to have a non-empirically grounded model say anything about the real world. Such models represent bogus or pseudo-knowledge. ${ }^{43}$

One implication is that the model's mathematical form is not derived by analogy or based on a metaphor, both of which are not constrained by reality. A second is that the model is an accurate, but reflective, description of the grounded theory and its data and therefore not a simplification of it. ${ }^{44}$ And a third is that the economic model is constructed in terms of historical time. That is, the economic model cannot be mathematically framed to deal with theoretical problems that do not exist in the data - grounded models do not permit the making up of fictitious theoretical problems which are then solved for. This means that it must be open in order to deal with real historical events and contribute to the historical narrative which also means that economic models just cannot be anything, rather they must be empirically-historically something. Additional implications are that the 
relationships between the variables in the model are derived from the empirically grounded theory as opposed to being assumed fictions, that the same model is used in both theoretical and applied work, that the model does not operate mechanistically like a machine, and that different grounded economic theories have different models. Consequently the mathematical-theoretical arguments and the measurable and observable numerical outcomes derived from the model are determined, constrained, and real. In particular, the outcomes of the model are not logical deductions from given axioms or unique (or multiple) mathematical solutions; rather they are non-logical empirically grounded outcomes. Such mathematical-theoretical arguments and models derived from empirically grounded theories are characterized as rigorous and non-deductive. Thus, this form of mathematical argument cannot be used to transform economic reasoning and explanation into mathematical formalism with its chains of mathematical-deductive reasoning.

Being isomorphic with the theory and its data, yet an alternative representation of the theory, a model can be used by the economist to obtain a better understanding of the theory itself as well as an analytical-narrative summary for pedagogical purposes. In addition, it can be used to examine and evaluate propositions found in the theoretical literature. That is, the mathematical-theoretical arguments derived from a rigorous economic model can be used to examine whether particular mathematical-theoretical propositions associated with different economic theories and models are also rigorous or have no empirical grounding hence real world existence. Because it is grounded in the existing data, it is independent of new and future data. Thus, it can be used, for example, for discussing economic policies and simulating their possible impacts on future economic events. In particular it is a way of visually picturing the economy and simulating its evolving, moving outcomes. Economic models can also be used to see whether the resulting outcomes of new data conform to the expected outcome patterns of the theory and to explore the impact of changing 
structures and causal mechanisms on economic outcomes. In this last case, for example, if a structure is hypothetically altered so that the economic model produces hypothetical different outcomes, the outcomes can then be compared to actual outcomes. If they seem to be the same, then the structures of the theory need to be re-examined and the process of grounding the theory renewed. [Weintraub 1998a, 1998b, 2001, 2002; Israel 1981, 1991; Boylan and O'Gorman 1995; Boland 1989; Dupre' 2001; Morrison and Morgan 1999; Eichner 1987; Carrier 1992; Setterfield 1995; Bunge, 1983a]

\section{Econometrics}

The tenets of critical realism and the grounded theory method also constrain econometrics to use as a statistical tool to assist the development and delineation of causal mechanisms and to evaluate the adequacy of grounded economic theories. ${ }^{45}$ In the process of transforming the empirically grounded categories into an economic theory, the economist will provisionally identify structures and causal mechanisms with particular transfactual outcomes. To aid them in their identification, the economist may subject the causal mechanism and its outcomes to econometric testing. The econometric model used will include components for the quantitative representation of structures as well as components for the causal mechanism; and its particular statistical form will be determined by the causal mechanism. If the econometric tests support the existence of the causal mechanism's transfactual outcomes, then the empirical grounding of the causal mechanism is enhanced. Failure of the tests would, on the other hand, indicate that the causal mechanism and its associated structures are inadequately developed and needed further development. Assuming the testing a success and in light of the other qualitative and quantitative empirical support, the economist can provisionally identify the causal mechanism and its transfactual outcomes. At this stage, they can engage in further theoretical sampling to see if additional qualitative and quantitative 
evidence support it; and econometric testing can again be utilized in this context. Thus econometric testing is not about future predictions, as the economy is open and always changing, but about understanding the relationship between the causal mechanism and its transfactual outcomes. If econometric testing of new data fails to support the causal mechanism and its outcomes, then the implication is that the structures and causal mechanisms have changed; it then becomes necessary to re-ground them.

Econometrics is also useful for evaluating grounded theories that may be associated with demi-regularities. ${ }^{46}$ In this case, the economic theory will be modeled so as to include all the structures, the primary causal mechanism, and the secondary causal mechanisms. If the testing is a success, then it can be more strongly argued that there exists a demi-regularity associated with the primary causal mechanism of the theory. But if the testing is not successful, then all that can be said is that it is less likely that the theory has a demi-regularity. Hence econometric testing provides a way to evaluate the continual correspondence of the theory with the real causes of ongoing economic events. By doing so, it contributes to the promotion of new theory building when the correspondence between theory and events break down. [Lawson 1989; Downward 1999, 2003; Downward and Mearman 2002; Lee and Downward 1999; Yeung 1997]

\section{HISTORICAL CHARACTER OF HETERODOX ECONOMIC THEORIES}

The common sense propositions combined with realism and critical realism exclude, as part of heterodox theorizing, ahistorical, atemporal entities and theoretical concepts, atemporal diagrams, given known ends independent of means or processes to attain them, models and other forms of analysis unaccompanied by temporal-historical analysis, and the utilization of ahistorical first principles or primary causes. Being outside of history, historical time, and an unknowable transmutable future, these ahistorical entities and concepts are also rejected by the grounded theory 
method as fictitious since they do not emerge as categories in the historical data. Consequently, ahistorical theories with their ahistorical concepts are not connected to the range of economic events they intend to explain and hence are not capable of explaining them. In contrast, the concatenated integration of the common sense propositions, realism and critical realism with the grounded theory method prescribes that heterodox theorizing include the delineation of historically grounded structures of the economy, and the development of historically grounded emergent causal mechanisms. When integrated together the resulting economic theories are grounded in and linked to critical realism. In addition, they are also historical theories in that they are historical narratives that explain the present or past internal workings of historical economic processes and events connected to the social provisioning process in the context of relatively stable causal mechanisms (whose actions and outcomes can be temporally different) and structures. That is, the simultaneous operation of primary and secondary causal mechanisms with different time dimensions ensures the existence of historical economic processes that are being explained. But even when the causal mechanism conclude their activity, the historical processes do not come to an end for the secondary and other causal mechanism can also have an impact on the structures so that the slowly transforming structures (and their impact on causal mechanisms) maintain the processes.

Historical processes are organized and directed by structures and causal mechanisms and are what constitutes historical time. Since those same structures and causal mechanisms also change slowly, historical processes change as well, implying that there are no end points, 'constants' to which the processes tend or lock-in, evolutionary pathways that must be followed irrespective of agency, or cyclical 'movements'. In short, historical change is non-teleological, non-historicist, noncyclical and hence just can only be change. With historical process and historical change as intrinsic properties of historical theories, such outside-of-history concepts and methods as equilibrium, 
optimization-maximization-minimization short-period/long-period positions, centers of gravitation, market clearing, states of rest, or comparative statics cannot be utilized to organize and direct economic inquiry and to narrate economic events. ${ }^{47}$ These concepts are sometimes theoretically justified in the context of a layered view of reality and economic events, since it allows some structures and mechanisms to exist essentially outside of time and historical process. At other times, they are justified in terms of slow moving variables (structures and causal mechanisms) and fast moving variables (outcomes) where the latter does not have an impact upon the former. However, the interplay and linkages between structures, causal mechanisms, and outcomes means that the distinction between the two kinds of variables is not sustainable and that consequently historical outcomes are not based on accidental, random, or autonomous factors; hence no structures, causal mechanisms, and outcomes can be independent of historical processes. In short, it is not possible to start with a static theory and dynamize it into a theory that explains historical processes — no amendments to an outside-of-history theory can transform it into a historical theory.

Historical economic theories are possible because, as argued in critical realism, all historical events are, due to the existence of structures and causal mechanisms, narratively structured-there are no accidental or uncaused events, that is, events without a narrative. Hence, heterodox economists do not impose narratives on actual economic events to make sense of them, but derive them from the events via the grounded theory method. ${ }^{48}$ Moreover, being a narrative, the theories have a plot with a beginning, middle, and end centered on a central causal mechanism and set within structures and other causal mechanisms. Therefore, antedated events prompt the causal mechanisms to initiate activity to generate particular results and hence start the narrative; and it comes to an end when the causal mechanisms conclude their activity. Finally, the storyteller of the narrative is the heterodox economist whose objective is to help the audience-who includes fellow economists, 
students, politicians, and the general public — understand theoretically how and why the actual economic events transpired. ${ }^{49}$ [Carr 1986; Bortis 1997; Eatwell 1998; Norman 1991; McCullagh 1984; Pentland 1999; Dey 1999; Appleby, Hunt and Jacob 1994, chs 7, 8]

As narratives linked with critical realism and centered on causal mechanisms and structures, historical heterodox theories are not completely aggregated or disaggregated; and nor are they devoid of explicit human intentionality and activity. That is, because causal mechanisms embody data from many case studies, they aggregate economic reality or, put differently, compact the scale of reality and therefore the degree of detail and specificity required of the narrative. However, the degree of aggregation is limited because of the existence of structures and causal mechanisms that cannot be aggregated or disaggregated and human intentionality and activity that are both differentiated and specific. As a result, heterodox economic theories are neither an aggregate theory where the differentiation among the causal mechanisms, structures, and human agency disappear; nor such a disaggregated theory so that causal mechanisms, structures, and human agency are individual-event specific and hence of little interest. ${ }^{50}$ The impossibility of aggregating emergent entities to produce representational aggregate entities, that is, aggregate entities with the same properties and behavior as the individual entities, means that heterodox economic theory must consist of linked causal mechanisms and structures. Thus, heterodox theories tell quasi-aggregated narratives explaining the many and overlapping actual economic events occurring in a differentiated economy. ${ }^{51}$

\section{THE MAKING OF HETERODOX MICROECONOMIC THEORY}

Heterodox economic theory is a encompassing theoretical explanation of the social provisioning process within the context of a capitalist economy and therefore is concerned with explaining those factors that are part of the process; and heterodox microeconomic theory is one component of the whole. To use critical realism and the method of grounded theory to develop a 
microeconomic theory means first delineating the empirically grounded causal mechanisms and structures that make up the constituent parts of the economy and their interdependencies; and secondly developing theories or analytical narratives of how they contribute to explaining the social provisioning process. Thus, the research and referencing requirements for developing an empirically grounded microeconomic theory are significant; and in some instances the necessary empirical evidence does not yet exist. ${ }^{52}$ Consequently, the microeconomic theory presented in the subsequent chapters will only be partially empirically grounded, leaving further work for heterodox economists to do. But what will become apparent is that the empirical stipulation of the structures and causal mechanisms will have a significant impact on a number of theoretical issues and arguments in heterodox economics. That is to say, the use of grounded theory only 'permits' specific structures and causal mechanisms to emerge which in turn constrains the range of theoretical models, arguments, and narratives that can contribute to understanding the social provisioning process in actual capitalist economies. This means that various arguments, models, and theories that had a historical explanatory role in heterodox economics will be put to the side. This will inevitably generate misgivings among heterodox economists as they may well ask 'what theory, friends, is this?'. It needs to be recognized that all knowledge is contestable and that even respected arguments and theories by great heterodox economists are not immune to questioning and being discarded.

To start the process of theory creation, the next chapter will delineate a theoretical picture of a capitalist economy that will serve as the foundation for developing an empirically grounded microeconomic theory of the social provisioning process as well as an empirically grounded model of the economy. This involves delineating the core structures of a capitalist economy relevant to the social provisioning process and locating within them the organizations, institutions, and agency that direct, engage in, or facilitate the economic events that result in social provisioning. And the 
economic events of specific interest are those that affect the production, pricing, demand, and distribution of goods and services. The structures help shape and govern economic events while the organizations and social institutions (that are located in the structures) house the causal mechanisms in which agency is embedded. What these structures, organizations, and agencies are will in part determine the kind of heterodox microeconomic theory that is developed. The core structures include the structure of production and the surplus and the structure of the linkages between incomes and the surplus; the core organizations and social institutions relevant to the social provisioning process and embedded in the structures include the business enterprise, market organizations such as cartels, family, and the state; and the core agents or agency whose decisions direct and/or reproduce the social provisioning process include the business and political elite and the household. The subsequent chapters represent four of the 'core' components of the theory--the business enterprise, the business enterprise and the market, and market governance, and the economy qua social provisioning process as a disaggregated, interdependent whole. More specifically, the first three core areas concentrate on delineating 'micro' structures and causal mechanisms and developing substantive and formal theories of the business enterprise (chapters three and four), of market demand (chapter five), and of market governance (chapter six). With the structures, causal mechanisms, and substantive theories in place, the final step is to develop a holistic heterodox microeconomic theory (chapters seven and eight) that brings together the constituent parts of the economy and their interdependencies. This will involve integrating the productive and monetary structures of the social provisioning process, the price model, and the output-employment model into a model of a going economy as a whole. Then, it will be possible to develop analytical narratives of the social provisioning process. In particular, the theory and the model together will then be utilized to delineate the impact of the 'micro' - that is prices, profit mark ups, finance, and investment--on 
the overall level of economic activity and hence on the social provisioning process.

\section{END NOTES}

${ }^{1}$ There is a debate within heterodox economics on whether heterodox and mainstream economics are really different or to some degree compatible, commensurable (Lee 2011a, 2011b). Those who advocate the latter position discount the theoretical critiques and ignore the clearly articulated statements by various heterodox economists, especially Marxists, radical Institutionalists, and Post Keynesian-Sraffians, who claim the form position.

${ }^{2}$ In some cases, concepts and their derivative symbols are presented in such a way so as to look like they are quantifiable, such as the utility function and "U" for total amount of utility. However, "U" is not well-defined, has no dimensions, and its units of measurement are not stated. This is a case of pseudoquantitation. [Bunge, 1998; Mahner, 2007]

${ }^{3}$ To illustrate, consider the heterodox critiques of the mainstream concept of scarcity. The Post Keynesians (Bortis 1997) argue that produced means of production within a circular production process cannot be characterized as scarce and that production is a social process; while Institutionalists (DeGregori 1987) reject the view that natural resources are not socially created to enter into the production process; and the Marxists (Matthaei 1984) argue that the concept is a mystification and misspecification of the economic problem - that it is not the relation of the individual to given resources, but the social relationships that underpin the social provisioning process. The three critiques are complementary and integrative and generate the common conclusion that the concept of scarcity must be rejected as well as the mainstream approach to the study of the social provisioning process in terms of the allocation of scarce resources among competing ends in light of unlimited wants. This is the basis to the popular statement that the only thing heterodox approaches have in common with each other is their opposition to mainstream economics. But if 
they have similar and overlapping critiques, then there is a good possibility that their positive analyses of the social provisioning process are also similar and integrative to some extent. This is, after all, the basis for heterodox economics.

${ }^{4}$ Other characteristics of a scientific research field include intimate relations (as opposed to imperialistic relations) with other research fields, direction of scientific activity determined internally to the research field as opposed to compliance to government, ecclesiastical, or business demands, and an ethos of free search for truth rather than an ethos of ideological faith, a quest for power or consensus, or an enforced blindness of the research community to alternative theories. Mainstream economics falls short on all three accounts, most notably in countries subject to national research assessment exercises and where state power is used to legitimate particular approaches in a research field. [Lee, 2009; Bunge 1998; Mahner 2007]

${ }^{5}$ This suggests that heterodox economists are relatively indistinguishable from their mainstream brethren except for their scientific output. There is, however, a difference. Being theoretically different often brings the individual heterodox economist under attack if he/she works in a predominately mainstream department. It also brings heterodox departments under attack by university administrators (and often times supported by mainstream economists) who are concerned about department rankings and the production and teaching of 'improper' or low-value knowledge. For a detailed history of such incidents, see Lee (2009).

${ }^{6}$ Gaddis (2002: 10).

${ }^{7}$ Since its beginnings in the 1960s and particularly since 1990, heterodox economists have been melding together aspects of different heterodox approaches, see Lee $(2009,2010)$.

${ }^{8}$ A number of elements constitute the theoretical core of heterodox theory. Some elements are clearly 
associated with particular heterodox approaches as noted by Phillip O’Hara:

The main thing that social economists bring to the study [of heterodox economics] is an emphasis on ethics, morals and justice situated in an institutional setting. Institutionalists bring a pragmatic approach with a series of concepts of change and normative theory of progress, along with a commitment to policy. Marxists bring a set of theories of class and the economic surplus. Feminists bring a holistic account of the ongoing relationships between gender, class, and ethnicity in a context of difference....And post-Keynesians contribute through an analysis of institutions set in real time, with the emphasis on effective demand, uncertainty and a monetary theory of production linked closely with policy recommendations.

(O’Hara 2002: 611)

However, other core theoretical elements--the socially embedded economy, the economy as an emergent system comprised of sub-systems, circular production, and cumulative change--emerge from a synthesis of arguments that are associated only in part with particular heterodox approaches. For a more detailed discussion of heterodox 'metaparadigm' theory building, see Lee $(2009,2010)$; also see Gioia and Pitre (1990) and Lewis and Grimes (1999).

${ }^{9}$ This position has a long lineage reflecting the influence of Karl Marx, Michael Kalecki, and Piero Sraffa; and since 1970 a number of heterodox economists have contributed to this tradition, including Kregel (1975), Pasinetti (1981, 1993), Eichner (1987), and Bortis, (1997). As a result, much of what is covered in this book can also be found in the works of these authors. This is particularly the case for Eichner.

${ }^{10}$ For example, dealing with the business enterprise and changes in anti-trust laws is not per se microeconomics and dealing with government expenditure decisions and fiscal policy is not per se 
macroeconomics, which means that fiscal policy in principle is of no more or less important that antitrust policy; rather they are differently important.

${ }^{11}$ The contrast to a factual theory is a theory which is concern exclusively with conceptual objects (scarcity) that have no connection to the real world or with theoretical objects (utility functions) that are explicitly divorced from the real world.

${ }^{12}$ This implies that agency qua decision making is an objective activity as opposed to a purely subjective one, as found in the work of radical subjectivist Austrian economists and in variants of mainstream economics. Hence, preference for 'objective' structures over 'subjective' agency and causal mechanisms in modeling and theorizing by some heterodox economists is rejected. [Sraffa 1960; Pasinetti 1981, 1993; Kurz and Salvadori 1995, 2005; Lewis 2005]

${ }^{13}$ Because its components are intentionally related, a causal mechanism cannot be thought of as a machine or 'mechanistic' - see Cartwright (1995) and Dupre' (2001) on machines and economic thinking.

${ }^{14}$ This property of causal mechanisms obviates the need for an inductivist approach for theory creation. Consequently, any method of theory creation and development, such as abduction, retroduction or the method of grounded theory, utilized in conjunction with critical realism will not adopt an inductivist strategy leading to invariant laws. [Sayer 1992]

${ }^{15}$ The Sraffian-classical long period methodology is also based on slowly changing structures; however, it does not include 'slowly changing' agency and the interaction between agency and structures. As a result, the theoretical entities determined by the structures are distinct from the actual entities that are determined by agency, such as long period prices and actual market prices. The critical realist structure-agency methodology eliminates this distinction so that the entities are 
both theoretical and actual: which means that actual market prices are 'structurally' stable but also change slowly over time.

${ }^{16}$ An alternative way of proceeding is to pursue the Babylonian method, but it is underdeveloped in that it advocates utilizing various research strategies to gather data from different sources, but then does not say how the data is transformed into a theory. Another alternative approach is to utilize retroduction as the methodological guideline for theory creation. Retroduction is a form of reasoning or theory construction that goes behind the surface phenomena to its causes. It involves first a theoretical-abstract re-description of the events based on existing qualitative and quantitative material; followed by explaining the events through postulating and identifying the structures and causal mechanisms producing them; and ending with the theory being checked empirically.

Although advocated, few critical realists have explicitly used it for theory construction; and when they have (for example Lawson 1998c), the results looks like a case study carried out according to the method of grounded theory. This is because retroduction is also too undeveloped to be used as a way to identify causal mechanisms and structures from which to construct theories or explanations. In addition, it does not indicate how the causal processes should be delineated and articulated, that is the analytical and literary form the theory should take. Finally, retroduction, as articulated by critical realists, suggests that analogies, similes, and metaphors are useful ways to identify causal mechanisms and structures. But since the latter are by their nature not real, their contribution to theory construction is at best limited and may inadvertently direct the attention of the critical realist heterodox economist towards fictitious, hence empirically ungroundable, mechanisms and structures. [Dow 1985, 1990a, 1990b, 2001; Lawson 1996, 1997b, 1998c, 1999b, 2003; Sarre 1987; Sayer 1992; Pratt 1995; Boylan and O'Gorman 1995; Yeung 1997; Runde 1998; Downward 1999] 
${ }^{17}$ The method of grounded theory was first delineated by Barry Glaser and Anselm Strauss (1967) and then subsequently developed by them and others--see Strauss (1987), Strauss and Corbin (1990, 1994), Dey (1999), Locke (2001), Goulding (2002), Bryant and Charmaz (2007). Similar methodological guidelines going by the names of holism, pattern model, method of structuredfocused comparison, and participant-observer approach using case study method were also proposed and developed at roughly the same time--see Diesing (1971), Wilber and Harrison (1978), George (1979), and Fusfeld (1980). Finally, historical economic theories based on pattern models were articulated by Arthur Spiethoff and members of the German Historical School—see Betz (1988), Spiethoff (1952, 1953), and Hodgson (2001).

${ }^{18}$ What grounded theory is not about is forcing data into pre-determined set of theoretical categories; all categories have to be empirically justified.

${ }^{19}$ Observable data is not solely restricted to sense experience. For example, historical documents or field reports contain data that cannot be verified by the reader's sense experience. The same can also be said for oral histories that deal with past events. On the other hand, non-written data, such as informal rules, hierarchical power, and expectations inside the business enterprise, are not unobservable in that they can be verbally articulated and hence written down, filmed and then identified at a later point in time, or observed as institutions, that is, as observable patterns of behavior hence capable of being recorded. Thus all data is observable, although the sources and medium in which they exist varies; to be unobservable in this sense is not to be real and hence to be no data at all.

${ }^{20}$ Constant comparison can also involve exact replicating previous studies to see how robust they are.

${ }^{21}$ Another way of putting this is that a category represents a 'pattern' that the economist has 
recognized in the data generated by replicatory or comparable studies. Thus categories are created by the economist rather than 'discovered' in the data; hence categories are one conceptual outcome that arises from the economist's immersion in the data. It is in this sense that categories emerge from the data. [Dey 2007]

${ }^{22}$ In either case, the language used to describe the categories may be quite different from the existing theoretical language. In particular, the building of a grounded theory may require the creation of a new language and discarding old words and their meanings. On the other hand, the language used may come directly from the data collected and/or from commonly used language (which is generally not theoretical language). [Konecki 1989; Coates 1996]

${ }^{23}$ The point of theoretical sampling is specifically to find data to make categories denser, more complex. Since the aim of the grounded theory method is to build theories based on data collected, the issue of generalizing in a statistical sense is not relevant. Thus theoretical vs. statistical sampling has no importance for the method. [Glaser and Strauss 1967; Corbin and Strauss 1990]

${ }^{24} \mathrm{~A}$ saturated category is not a function of the number of pieces of data, as it may become saturated after only a small portion of the available data has been analyzed. Non-parametric statistical techniques can be used to judge whether a category is saturated or not--see Finch and McMaster (2002).

${ }^{25}$ Thus, the grounded theory method is not the same as induction; and its practitioners view generalization as a problematic and unimportant goal. Moreover, since it is compatible and integrated with critical realism, it cannot generate an inductivist strategy leading to empiricaltheoretical laws. [Sarre 1987; Sayer 1992]

${ }^{26}$ The irrelevance of logical coherence means that it is not possible to deduce unknown structures and 
causal mechanisms from existing ones.

${ }^{27} \mathrm{~A}$ formal grounded theory is not more (or less) abstract than a substantive grounded theory. Because a grounded theory must at all times be grounded, it can not be an abstract theory where the modifier denotes some degree of non-groundness, such as the use of fictional categories or the elimination of data. Hence grounded theories cannot be differentiated according to their levels of abstraction.

${ }^{28}$ This requirement means that heterodox economists need to be familiar with the theoretical approaches of many of the heterodox approaches as well as their intellectual histories.

${ }^{29}$ By accepting that it may be necessary to cast aside previously acquired knowledge, the economist can still pursue the grounded theory method even though they may favor particular non-grounded concepts and theories. Hence the grounded theory economist is not a neutral observer sifting through given "facts" that present him, through some sort of immaculate conception, with a theory without a moment of forethought; rather the economist is actively and reflectively engaged with it.

${ }^{30}$ This clearly implies that grounded theories are not instrumental theories, even though they share the property of being neither true nor false.

${ }^{31}$ This social engagement does not always ensure that adequate theories emerge, but it is indispensible to the evaluation process.

${ }^{32}$ The often-heard phrase that "all theory is in some sense unrealistic" is not applicable to grounded theories. All grounded theories are realistic in that they are grounded in every detail in data. A grounded theory may be relatively complete or a much incomplete explanation of an economic event; but in both cases they are entirely realistic. To be unrealistic from a grounded theory perspective is to include non-grounded concepts in the theory, but then it would not be grounded. 
${ }^{33}$ This has been called pattern-matching in that the existing theory is seen as a particular pattern of data and narrative and the new pattern of data with its narrative is compared to it to see if they match-see Wilber and Harrison (1978) and Yin (1981a, 1981b).

${ }^{34}$ The expectation of the grounded theory method is that the economist will seriously consider alternative combinations of structures and causal mechanisms before settling on a particular theory. ${ }^{35}$ For example, from a critical realist-grounded theory perspective, an assumption-based isolative theory is without empirical grounding and hence has no real world sense or meaning.

${ }^{36}$ Created data does not pre-exist as some sort of unacknowledged sense experience or as unobservable data; rather being produced, it has no past. Moreover, since economists create data, they have a direct and reflexive relation to it.

${ }^{37}$ Thus, the Sraffian position that subjective evaluations and expectations are non-observables is rejected.

${ }^{38}$ The combination of different types of data derived from different research methods is also called triangulation. [Thurmond 2001; Downward and Mearman 2007; Olsen 2003]

${ }^{39}$ It is important to realize that a case study which involves the replication and re-evaluation of a previous case study is theoretical sampling. In this instance, the researcher is re-examining an existing case study to see how robust its data and results are.

${ }^{40}$ This type of case study is similar to the extended case method advocated by Burawoy $(1991,1998)$, with the caveat that the latter is predicated on a false dichotomy between structures and causal mechanisms, where structures change independently of causal mechanism, not in part because of them.

41 One implication of this position is that an economic model is no better than the theory it reflects. 
So if the theory is ungrounded and/or theoretically incoherent, then so will be its economic models.

${ }^{42}$ This relationship between mathematics and empirically grounded theory is similar to the late nineteenth century view in which mathematical rigor was established by basing the mathematics on physical reasoning resulting in physical models. However, the difference here is that rigor results when the mathematical model is based on social reasoning represented by empirically grounded theory.

43 This approach to economic models and their contribution to economic analysis and explanation of the social provisioning process is distinct from how mainstream economists utilize models. Mainstream economists mostly do not empirically ground their models, but prefer to embed them in a hypothetical fantasy-based reality which they believe qua have (religious) faith in are credible representations of the real world. But at other times, they base their models upon single exemplary case study or 'stylized' facts that are not subject to constant comparisons to additional data; so rendering their models no more credible than entirely empirically groundless models. However, in both cases the credibility of the models are enhanced by allegorical stories they tell. In short, from a grounded theory perspective, mainstream economists are engaged in wrong modeling and have done so for the past hundred years. [Sugden 2002: 131; Morgan 2002, 2007, 2009a, 2009b] ${ }^{44} \mathrm{~A}$ model that simplifies a grounded theory does not accurately and concretely denotes its structures and leaves its causal mechanisms under-specified, under-embedded and thus ill-defined.

${ }^{45}$ Econometric testing can also be used to evaluate particular claims in the historical literature regarding causal mechanisms and transfactual outcomes.

${ }^{46}$ Non-parametric statistics can also contribute to the analysis of demi-regularities and to measures of the nature of any relationship between demi-regularities cast into a contrastive relationship. [Finch 
and McMaster, 2002]

${ }^{47}$ This conclusion applies to mainstream theory as well as to various heterodox approaches: for example: Sraffian long period positions and Post Keynesian short period positions.

${ }^{48}$ As long as historical events are narratively structured, subjectivity, uncertainty, and expectations do not introduce indeterminacy into heterodox theories.

${ }^{49}$ The historical character of heterodox economic theories is closely aligned with the view of economic theories espoused by the German Historical School (Betz 1988; Spiethoff 1952, 1953).

${ }^{50}$ The outcome of a grounded theory approach to constructing causal mechanisms is a rejection of methodological individualism. While individual agents make decisions based on subjective and objective evaluations of a somewhat uncertain future and generate outcomes, for theoretical purposes, their decisions and outcomes are aggregated and embedded in a causal mechanism. Hence, the empirically grounded role of the subjective and the uncertainty in the causal mechanism is observable, persistent, and systematic.

${ }^{51}$ See Dopfer and Potts (2008: 21-26) for a similar argument regarding meso and macro.

${ }^{52}$ The referencing requirements are so great for grounded theorizing that it is not possible to reference all the empirical evidence. Hence only some of the evidence will be referenced in the book. 


\section{REFERENCES}

Ackerman, F. and Nadal, A. (2004) The Flawed Foundations of General Equilibrium: critical essays on economic theory. London: Routledge.

Annells, M. (1996) 'Grounded Theory Method: Philosophical Perspectives, Paradigm of Inquiry, and Postmoderism', Qualitative Health Research, 6: 379-93.

Appleby, J., Hunt, L., and Jacob, M. (1994) Telling the Truth About History, New York: W. W. Norton and Company.

Arestis, P. (1996) 'Post-Keynesian Economics: Towards Coherence', Cambridge Journal of Economics 20(1): 111-35.

Atkinson, G. W. and Oleson, T. (1996) 'Institutional Inquiry: the search for similarities and differences', Journal of Economic Issues, 30(3): 701-18.

Betz, H. K. (1988) 'How Does the German Historical School Fit?’ History of Political Economy, 20(3): 409-30.

Bigus, O. E., Hadden, S. C., and Glaser, B. G. (1994) 'The Study of Basic Social Processes', in B. G. Glaser (ed.) More Grounded Theory Methodology: a reader, 38-64, Mill Valley: Sociology Press.

Boland, L. (1989) The Methodology of Economic Model Building: methodology after Samuelson, London: Routledge.

Bortis, H. (1997) Institutions, Behaviour and Economics Theory: a contribution to ClassicalKeynesian political economy, Cambridge: Cambridge University Press.

Boylan, T. and O'Gorman, P. (1995) Beyond Rhetoric and Realism in Economics: towards a reformulation of economic methodology, London: Routledge. 
Bryant, A. and Charmaz, K. (eds) (2007) The SAGE Handbook of Grounded Theory, Los Angeles: SAGE Publications.

Bunge, M. (1983a) Epistemology and Methodology I: Exploring the world, Boston: D. Reidel Publishing Company. (1983b) Epistemology and Methodology II: Understanding the world, Boston: D. Reidel Publishing Company. (1985) Epistemology and Methodology III: Philosophy of Science and Technology, Part II Life Science, Social Science and Technology, Boston: D. Reidel. (1998) Social Science under Debate: a philosophical perspective, Toronto: University of Toronto Press.

Burawoy, M. (1991) 'The Extended Case Method', in M. Burawoy Ethnography Unbound, 271-87, Berkeley: University of California Press. (1998) 'The Extended Case Method', Sociological Theory, 16(1): 4-33.

Carr, D. (1986) 'Narrative and the Real World: an argument for continuity', History and Theory: studies in the philosophy of history, 25(2): 117-31.

Carrier, D. (1992) ‘A Methodology for Pattern Modeling Nonlinear Macroeconomic Dynamics', Journal of Economic Issues, 26(1): 221-242.

Cartwright, N. (1995) 'Ceteris Paribus Laws and Socio-Economic Machines', The Monist, 78(3): 276-94.

Charmaz, K. (1983) 'The Grounded Theory Method: An Explication and Interpretation', in R. M. Emerson (ed.) Contemporary Field Research: a collection of readings, 109-26, Boston: Little, Brown and Company. 
Coates, J. (1996) The Claims of Common Sense: Moore, Wittgenstein, Keynes and the social sciences. Cambridge: Cambridge University Press.

Conrad, C. F. (1978) 'A Grounded Theory of Academic Change', Sociology of Education, 51: 10112.

Corbin, J. and Strauss, A. (1990) 'Grounded Theory Research: procedures, canons, and evaluative criteria', Qualitative Sociology, 13: 3-21.

Davidson, P. (1996) 'Reality and Economic Theory', Journal of Post Keynesian Economics, 18(4): 479-508.

DeGregori, T. R. (1987) 'Resources Are Not: They Become: An Institutional Theory', Journal of Economic Issues, 21(3): 1241-1263.

Dey, I. (1999) Grounding Grounded Theory: guidelines for qualitative inquiry, San Diego: Academic Press. (2007) 'Grounding Categories,' in A. Bryant and K. Charmaz (eds) The SAGE Handbook of Grounded Theory, 167-190, Los Angeles: SAGE Publications.

Diesing, P. (1971) Patterns of Discovery in the Social Sciences, New York: Aldine.

Dobb, M. 1945. Political Economy and Capitalism: Some essays in economic tradition, New York: International Publishers.

Dopfer, K. and Potts, J. (2008) The General Theory of Economic Evolution, London: Routledge.

Dow, S. C. (1985) Macroeconomic Thought: a methodological approach, Oxford: Basil Blackwell. (1990a) 'Post-Keynesianism as Political Economy: a methodological discussion,' Review of Political Economy, 2(3): 345-58. (1990b) 'Beyond Dualism,' Cambridge Journal of Economics, 14(2): 143-57. 
(1999) 'Post Keynesianism and Critical Realism: what is the connection?' Journal of Post Keynesian Economics, 22(1): 15-34.

(2001) 'Post Keynesian Methodology,' in R. F. Holt and S. Pressman (eds) A New Guide to Post Keynesian Economics, 11-20, London: Routledge.

Downward, P. (1999) Pricing Theory in Post Keynesian Economics: a realist approach, Cheltenham: Edward Elgar. (ed.) (2003) Applied Economics and the Critical Realist Critique, London: Routledge.

Downward, P. and Mearman, A. (2002) 'Critical Realism and Econometrics: constructive dialogue with Post Keynesian Economics', Metroeconomica, 53(4): 391-415. (2007) 'Retroduction as Mixed-Methods Triangulation in Economic Research: reorienting economics into social science', Cambridge Journal of Economics, 31(1): 77-99.

Dugger, W. M. (1996) 'Redefining Economics: from market allocation to social provisioning', in C. Whalen (ed.) Political Economy for the $21^{\text {st }}$ Century: contemporary views on the trends of economics, 31-43, Armonk: M. E. Sharpe, Inc.

Dupre', J. (2001) 'Economics Without Mechanism', in U. Maki (ed.) The Economic World View: studies in the ontology of economics, 308-32, Cambridge: Cambridge University Press.

Eatwell, J. 1998. 'Natural and normal conditions.' In The New Palgrave: A dictionary of economics, Vol. 3, edited by J. Eatwell, M. Milgate, and P. Newman, 598-599. London: Palgrave Macmillan.

Eichner, A. S. (1987) The Macrodynamics of Advanced Market Economies, Armonk: M. E. Sharpe, Inc.

Eisenhardt, K. M. (1989) ‘Building Theories from Case Study Research’, Academy of Management 
Review, 14(4): 532-50.

Ellis, B. (1985) 'What Science Aims to Do', in P. M. Churchland and C. A. Hooker (eds) Images of Science, 48-74, Chicago: The University of Chicago Press.

Emigh, R. J. (1997) 'The Power of Negative Thinking: the use of negative case methodology in the development of sociological thinking', Theory and Society, 26: 649-84.

Finch, J. H. (1999) ‘The Methodological Implications of Post Marshallian Economics', in S. C. Dow and P. E. Earl (eds) Contingency, Complexity and the Theory of the Firm: essays in honour of Brian J. Loasby, 156-77, Cheltenham: Edward Elgar. (2002) 'The Role of Grounded Theory in Developing Economic Theory', Journal of Economic Methodology, 9(2): 213-34.

Finch, J. H. and McMaster, R. (2002) 'On Categorical Variables and Non-Parametric Statistical Inference in the Pursuit of Causal Explanations', Cambridge Journal of Economics, 26(6): $753-72$.

Fleetwood, S. (2001a) 'Causal Laws, Functional Relations and Tendencies', Review of Political Economy, 13(2): 201-20. (2001b) 'Conceptualizing Unemployment in a Period of Atypical Employment: a critical realist perspective', Review of Social Economy, 59(1): 45-69.

Foster, J. F (1981) 'The Relation between the Theory of Value and Economic Analysis', Journal of Economic Issues, 15(4): 899-905.

Fusfeld, D. R. (1980) 'The Conceptual Framework of Modern Economics', Journal of Economic Issues, 14(1): 1-52.

Gaddis, J. L. (2002) The Landscape of History, Oxford: Oxford University Press. 
George, A. L. (1979) 'Case Studies and Theory Development: the method of structured, focused comparison', in P. G. Lauren (ed.) Diplomacy: new approaches in history, theory, and policy, 43-68, New York: The Free Press.

Gioia, D. A. and Pitre, E. (1990) 'Multiparadigm Perspectives on Theory Building', The Academy of Management Review, 15(4): 584-602.

Glaser, B. G. (1992) Emergence vs Forcing: basics of grounded theory analysis, Mill Valley: Sociology Press. (2007) 'Doing Formal Theory,' in A. Bryant and K. Charmaz (eds) The SAGE Handbook of Grounded Theory, 97-113, Los Angeles: SAGE Publications.

Glaser, B. G. and Strauss, A. L. (1967) The Discovery of Grounded Theory: strategies for qualitative research, New York: Aldine Publishing Company.

Goulding, C. (2002) Grounded Theory: a practical guide for management, business and market Researchers, London: SAGE Publications.

Gruchy, A. G. (1987) The Reconstruction of Economics: an analysis of the fundamentals of Institutional economics, New York: Greenwood Press.

Hirshleifer, J. (1985) 'The Expanding Domain of Economics', American Economic Review, 75.6: 53-68.

Hodgson, G. M. (1998) 'Emergence', in J. B. Davis, D. W. Hands, and U. Maki (eds) The Handbook of Economic Methodology, 156-60, Cheltenham: Edward Elgar.

(2000) 'From Micro to Macro: The Concept of Emergence and the Role of Institutions', in L. Burlamaquiun, A. C. Castro, and H.-J. Chang (eds) Institutions and the Role of the State, 103-26, Cheltenham: Edward Elgar. 
(2001) How Economics Forgot History: the problem of historical specificity in social science. London: Routledge.

Hunt, S. D. (1994) 'A Realist Theory of Empirical Testing: resolving the theory-ladenness/objectivity debate', Philosophy of the Social Sciences, 24(2): 133-58.

Ingham, G. (1996) 'Money is a Social Relation', Review of Social Economy, 54(4): 507-29.

Israel, G. (1981) 'Rigor' and 'Axiomatics' in Modern Mathematics', Fundamenta Scientiae, 2: 20519. (1991) 'Volterra's ‘Analytical Mechanics' of Biological Associations', Archives Internationales d'Histoire des Sciences, 41(1): 307-352.

Joseph, J. (1998) 'In Defense of Critical Realism', Capital and Class, 65: 73-106.

Kanth, R. (1992) 'Economics and Epistemology: a realist critique', Capital and Class, 47: 93-112.

Keen, S. (2001) Debunking Economics: the naked emperor of the social sciences, New York City:

St. Martin's Press.

Konecki, K. (1989) 'The Methodology of Grounded Theory in the Research of the Situation of Work', The Polish Sociological Bulletin, 2: 59-74.

Kregel, J. A. (1975) The Reconstruction of Political Economy: an introduction to Post-Keynesian economics, 2nd edn, London: The Macmillan Press.

Kurz, H. D. and Salvadori, N. (1995) Theory of Production: a long-period analysis, Cambridge: Cambridge University Press. (2005) 'Representing the Production and Circulation of Commodities in Material Terms: on Sraffa's objectivism', Review of Political Economy, 17(3): 413-41. 
Lawson, C., Peacock, M., and Pratten, S. (1996) 'Realism, Underlabouring and Institutions', Cambridge Journal of Economics, 20(1): 137-51.

Lawson, T. (1989) 'Abstraction, Tendencies and Stylised Facts: a realist approach to economic analysis', Cambridge Journal of Economics, 13(1): 59 - 78.

(1994) 'The Nature of Post Keynesianism and its Links to other Traditions: a realist perspective', Journal of Post Keynesian Economics, 16(4): 503-38.

(1996) 'Developments in 'Economics as Realist Social Theory', Review of Social

Economy, 54(4): 405-22.

(1997a) Economics and Reality, London: Routledge.

(1997b) 'On Criticizing the Practices of Economists: a case for interventionist methodology',

in A. Salanti and E. Screpanti (eds) Pluralism in Economics: new perspectives in history and methodology, 13-36, Cheltenham: Edward Elgar.

(1998a) 'Tendencies', in J. B. Davis, D. W. Hands, and U. Maki (eds) The Handbook of Economic Methodology, 493-98, Cheltenham: Edward Elgar.

(1998b) 'Transcendental Realism', in J. B. Davis, D. W. Hands, and U. Maki (eds) The

Handbook of Economic Methodology, 504-10, Cheltenham: Edward Elgar.

(1998c) ‘Social Relations, Social Reproduction and Stylized Facts', in P. Arestis (ed.)

Method, Theory and Policy in Keynes: essays in honour of Paul Davidson, vol. 3, 17-43,

Cheltenham: Edward Elgar.

(1999a) 'Connections and Distinctions: Post Keynesianism and critical realism', Journal of

Post Keynesian Economics, 22(1): 3-14.

(1999b) 'Critical Issues in Economics as Realist Social Theory', in S. Fleetwood (ed.) 
Critical Realism in Economics: development and debate, 209-57, London: Routledge. (2003) Reorienting Economics, London: Routledge.

Lee, F. S. (2009) Challenging the Mainstream: essays on the history of heterodox economics in the twentieth century, New York: Routledge. (2010) 'Pluralism in Heterodox Economics,' in R. F. Garnett, E. K. Olsen, and M. Starr Economic Pluralism, 19-35, London: Routledge.

( 2011a) 'The Pluralism Debate in Heterodox Economics', Review of Radical Political Economics, 43(4): Forthcoming. (2011b) 'Heterodox Economics, Tolerance and Pluralism: A reply to Garnett and Mearman', Review of Radical Political Economics, 43(4): Forthcoming. (2011c) 'Introduction to Heterodox Production and Price Models,' Unpublished.

Lee, F. S. and Downward, P. (1999) 'Retesting Gardiner Means’s Evidence on Administered Prices', Journal of Economic Issues, 33(4): 861-86.

Lee, F. S. and Keen, S. (2004) 'The Incoherent Emperor: A Heterodox Critique of Neoclassical Microeconomic Theory', Review of Social Economy, 62(2): 169-99.

Lewis, M. W. and Grimes, A. J. (1999) 'Metatriangulation: building theory from multiple paradigms', The Academy of Management Review, 24(4): 672-90.

Lewis, P. A. (2005) 'Structure, Agency and Causality in Post-revival Austrian Economics: tensions and resolutions', Review of Political Economy, 17(2): 291-316.

Lloyd, C. (1993) The Structures of History, Oxford: Basil Blackwell Ltd.

Locke, K. (2001) Grounded Theory in Management Research, London: SAGE Publications Ltd. Lovering, J. (1990) 'Neither Fundamentalism nor 'New Realism': a critical realist perspective on 
current divisions in socialist theory', Capital and Class, 42: 30-54.

Mahner, M. (2007) 'Demarcating Science from Non-Science', in T. A. F. Kuipers (ed) General Philosophy of Science: focal issues, 515-75, Amsterdam: Elsevier B. V.

Maki, U. (1989) 'On the Problem of Realism in Economics,' Ricerche Economiche, 43(1-2): 176-98. (1990) 'Scientific Realism and Austrian Explanation,' Review of Political Economy, 2(3): $310-44$. (1992a) 'The Market as an Isolated Causal Process: a metaphysical ground for realism', in B. J. Caldwell and S. Boehm (eds) Austrian Economics: tensions and new directions, 35-59, Boston: Kluwer Academic Publishers. (1992b) 'On the Method of Isolation in Economics,' Poznaan Studies in the Philosophy of the Sciences and the Humanities, 26: 317-51. (1996) 'Scientific Realism and Some Pecularities of Economics,' in R. S. Cohen, R. Hilpinen, and Q. Renzong (eds) Realism and Anti-Realism in the Philosophy of Science, 42747, Dordrecht: Kluwer Academic Publishers. (1998a) 'Realism,' in J. B. Davis, D. W. Hand and U. Maki (eds) The Handbook of Economic Methodology, 404-09, Cheltenham: Edward Elgar. (1998b) ‘Aspects of Realism About Economics,', Theoria, 13(2): 310-19. (2001) 'The Way the World Works (www): towards an ontology of theory choice,' in U. Maki (ed.) The Economic World View: studies in the ontology of economics, 369-89, Cambridge: Cambridge University Press.

Matthaei, J. (1984) 'Rethinking Scarcity: Neoclassicism, NeoMalthusianism, and NeoMarxism', Review of Radical Political Economics, 16(2/3): 81-94. 
McCullagh, C. B. (1984) Justifying Historical Descriptions, Cambridge: Cambridge University Press.

(2000) 'Bias in Historical Description, Interpretation, and Explanation', History and Theory: Studies in the Philosophy of History, 39(1): 39-66.

Megill, A. (1989) 'Recounting the Past: 'Description,' Explanation, and Narrative in Historiography', American Historical Review, 94: 627-53.

Morgan, M. (2002) 'Models, Stories, and the Economic World', in U. Maki (ed) Fact and Fiction in Economics: Models, realism and social construction, 178-201, Cambridge: Cambridge University Press. (2007) 'Afterword: Reflections on exemplary narratives, cases, and model organisms', in A.

N. H. Creager, E. Lunbeck, and M. N. Wise (eds) Science Without Laws: Model systems, cases, exemplary narratives, 264-74, Durham: Duke University Press. (2009a) 'Models and Modelling in Economics,' Unpublished.

Http://papers.ssrn.com/sol3/papers.cfm?abstract_id=1499975. (2009b) ‘Modelling as a Method of Enquiry', Unpublished.

Http://www2.lse.ac.uk/economicHistory/pdf/Morgan/Morgan\%20Chap1\%20Modelling\%20a s\%20a\%20Method\%20of\%20Enquiry.pdf.

Morrison, M. and Morgan, M. S. (1999) 'Models as Mediating Instruments', in M. S. Morgan and M. Morrison (eds) Models as Mediators: perspectives on natural and social science, 10-37, Cambridge: Cambridge University Press.

Norman, A. P. (1991) 'Telling it Like it Was: historical narratives on their own terms', History and Theory: Studies in the Philosophy of History, 30(2): 119-35. 
O’Hara, P. A. (2002) 'The Role of Institutions and the Current Crises of Capitalism: a reply to Howard Sherman and John Henry', Review of Social Economy, 60(4): 609-18.

Olsen, W. (2003) 'Triangulation, Time and the Social Objects of Econometrics', in R. Downward (ed.) Applied Economics and the Critical Realist Critique, 153-69, London: Routledge.

Orum, A. M., Feagin, J. R., and Sjoberg, G. (1991) 'Introduction: the nature of the case study', in J. R. Feagin, A. M. Orum, and G. Sjoberg (eds) A Case for the Case Study, 1-26, Chapel Hill: The University of North Carolina Press.

Palacio-Vera, A. (2005) 'The 'Modern' View of Macroeconomics: some critical reflections', Cambridge Journal of Economics, 29.5: 747-67.

Pasinetti, L. L. (1981) Structural Change and Economic Growth: a theoretical essay on the dynamics of the wealth of nations, Cambridge: Cambridge University Press.

Pentland, B. T. (1999) ‘Building Process Theory with Narrative: From Description to Explanation', Academy of Management Review, 24(4): 711-24.

Petri, F. (2004) General Equilibrium, Capital and Macroeconomics: a key to recent controversies in equilibrium theory, Cheltenham: Edward Elgar.

Polanyi, K. (1968) ‘The Economy as Instituted Process', in G. Dalton (ed.) Primitive, Archaic and Modern Economies: essays of Karl Polanyi, 139-74, Garden City: Doubleday and Company, Inc.

Power, M. (2004) 'Social Provisioning as a Starting Point for Feminist Economics', Feminist Economics, 10(3): 3-19.

Pratt, A. (1995) 'Putting Critical Realism to Work: the practical implications for geographical research', Progress in Human Geography, 19: 61-74. 
Rizvi, S. A. T. (1994) ‘The Microfoundations Project in General Equilibrium Theory', Cambridge Journal of Economics, 18(4): 357-77.

Rotheim, R. J. (1999) 'Post Keynesian Economics and Realist Philosophy', Journal of Post Keynesian Economics, 22(1): 71-104.

Runde, J. (1998) ‘Assessing Causal Economic Explanations', Oxford Economic Papers, 50: 151-72.

Sarre, P. (1987) 'Realism in Practice', Area, 19: 3-10.

Sayer, A. (1992) Method in Social Science: a realist approach, 2nd edn, London: Routledge.

Scheibl, F. and Wood, A. (2005) 'Investment Sequencing in the Brick Industry: an application of grounded theory', Cambridge Journal of Economics, 29(2): 223-47.

Setterfield, M (1995) 'Historical Time and Economic Theory', Review of Political Economy, 7(1): 128.

Smith, L. M. (1998) 'Biographical Method', in N. K. Denzin and Y. S. Lincoln (eds) Strategies of Qualitative Inquiry, 184-224, Thousand Oaks: SAGE Publications.

Spiethoff, A. (1952) 'The 'Historical' Character of Economic Theories', The Journal of Economic History, 12(2): 131-39. (1953) 'Pure Theory and Economic Gestalt Theory: Ideal Types and Real Types', in F. C. Lane and J. C. Riemersma (eds) Enterprise and Secular Change: readings in economic history, 444-63, Homewood: Richard D. Irwin.

Sraffa, P. (1960) Production of Commodities by Means of Commodities, Cambridge: Cambridge University Press.

Stake, R. E. (1998) 'Case Studies', in N. K. Denzin and Y. S. Lincoln (eds) Strategies of Qualitative 
Inquiry, 86-109, Thousand Oaks: SAGE Publications.

Stevenson, R. E. (1987) 'Institutional Economics and the Theory of Production', Journal of Economic Issues, 21(4): 1471-93.

Strauss, A. L. (1987) Qualitative Analysis for Social Scientists, Cambridge: Cambridge University Press.

Strauss, A. and Corbin, J. (1990) Basics of Qualitative Research: grounded theory procedures and techniques, Newbury Park: Sage Publications. (1994) 'Grounded Theory Methodology: an overview', in N. K. Denzin and Y. S. Lincoln (eds) Handbook of Qualitative Research, 273-85, Thousand Oaks: Sage Publications.

Sugden, R. (2002) 'Credible Worlds: the status of theoretical models in economics', in U. Maki (ed) Fact and Fiction in Economics: Models, realism and social construction, 107-36, Cambridge: Cambridge University Press.

Thurmond, V. A. (2001) 'The Point of Triangulation', Journal of Nursing Scholarship, 33(3): 25358.

Tosh, J. (1991) The Pursuit of History, 2nd edn, London: Longman.

Tsang, E. and Kwan, K.-M. (1999) 'Replication and Theory Development in Organization Science: a critical realist perspective', Academy of Management Review, 24(4): 759-80.

Turner, B. A. (1981) 'Some Practical Aspects of Qualitative Data Analysis: one way of organising the cognitive processes associated with the generation of grounded theory', Quality and Quantity, 15: 225-47. (1983) 'The Use of Grounded Theory for the Qualitative Analysis of Organizational Behaviour', Journal of Management Studies, 20(3): 333-48. 
Vaughan, D. (1992) 'Theory Elaboration: the heuristics of case analysis', in C. C. Ragin and H. S. Becker (eds) What is a Case? exploring the foundations of social inquiry, 173-202, Cambridge: Cambridge University Press.

Weintraub, E. R. (1998a) 'From Rigor to Axiomatics: The Marginalization of Griffith C. Evans', in M. S. Morgan and M. Rutherford (eds) From Interwar Pluralism to Postwar Neoclassicism, 227-59, Durham: Duke University Press. (1998b) 'Controversy: Axiomatisches Mißverstandis', The Economic Journal, 108(451): $1837-1847$. (2001) 'Measurement, and Changing Images of Mathematical Knowledge', in J. L. Klein and M. S. Morgan (eds) The Age of Economic Measurement, 303-12, Durham: Duke University Press. (2002) How Economics Became a Mathematical Science, Durham: Duke University Press.

Wellman, B. and Berkowitz, S. D. (eds) (1997) Social Structures: a network approach, Greenwich: JAI Press Inc.

White, G. (2004) 'Capital, Distribution and Macroeconomics: 'core' beliefs and theoretical foundations', Cambridge Journal of Economics, 28(4): 527-47.

Wieviorka, M. (1992) 'Case Studies: History or Sociology?' in C. C. Ragin and H. S. Becker (eds) What is a Case? exploring the foundations of social inquiry, 159-72, Cambridge: Cambridge University Press.

Wilber, C. K. and Harrison, R. S. (1978) 'The Methodological Basis of Institutional Economics: pattern model, storytelling, and holism', Journal of Economic Issues, 12(3): 61-89. 
Wisman, J. D. and Rozansky, J. (1991) 'The Methodology of Institutionalism Revisited', Journal of Economic Issues, 25(3): 709-37.

Yeung, H. (1997) 'Critical Realism and Realist Research in Human Geography: a method or a philosophy in search of a method?' Progress in Human Geography, 21: 51-74.

Yin, R. K. (1981a) 'The Case Study Crisis: Some Answers', Administrative Science Quarterly, 26: $58-65$. (1981b) 'The Case Study as a Serious Research Strategy', Knowledge: Creation, Diffusion, Utilization, 3(1): 97-114. (1994) Case Study Research: design and methods, $2^{\text {nd }}$ edn, London: Sage Publications. 